\title{
TOMADA DE (IN) DECISÃO NAS ORGANIZAÇ̃̃ES
}

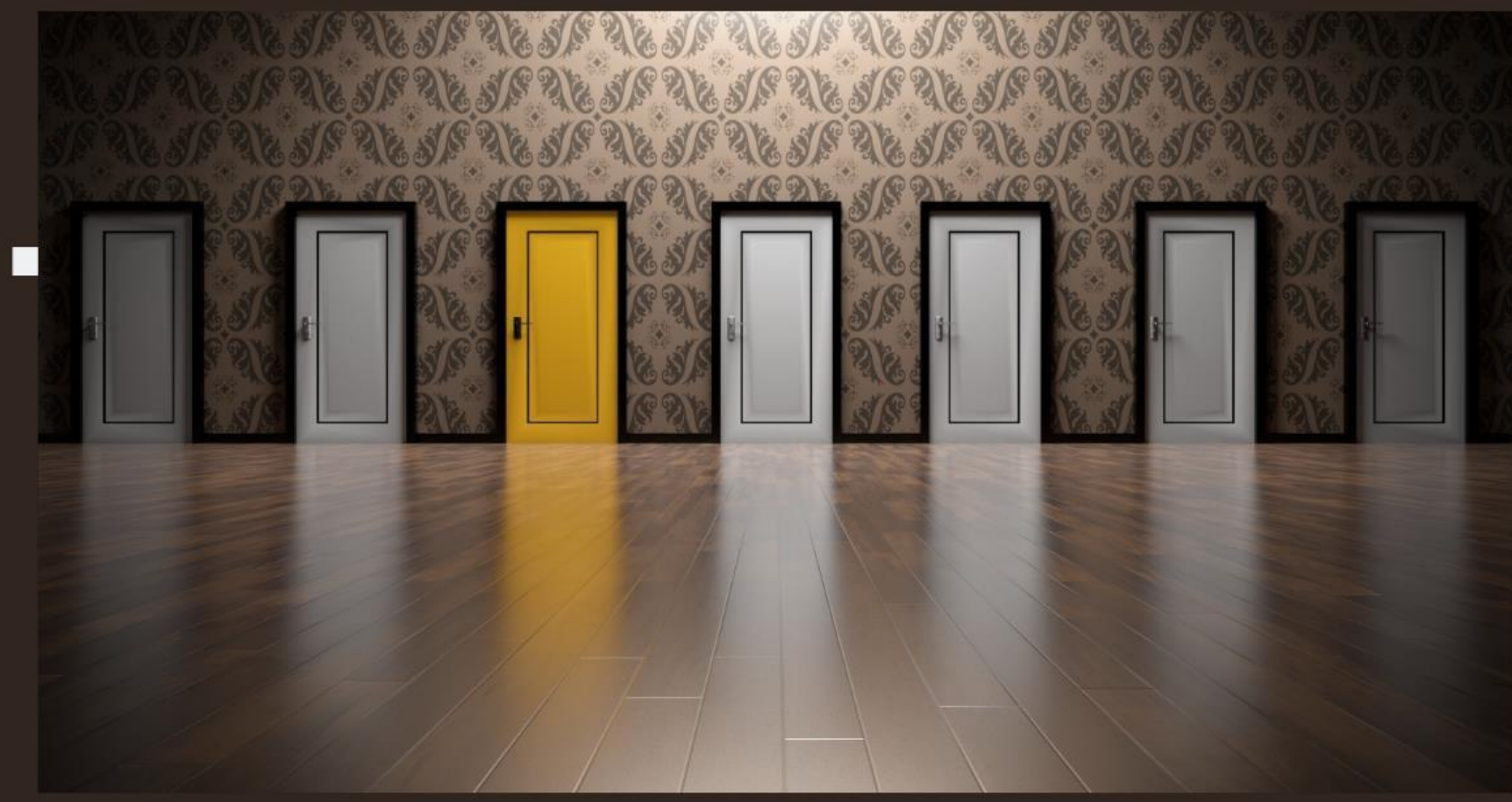

Elizângela de Jesus Oliveira

Rute Holanda Lopes

Móises Belchior

Marusca Wisler

(Organizadores) 
Organizadores:

Elizângela de Jesus Oliveira

Rute Holanda Lopes

Móises Belchior

Marusca Wisler

\section{Tomada de (In) decisão nas Organizações}

1a Edição

Belo Horizonte

Poisson

2020 
Editor Chefe: Dr. Darly Fernando Andrade

\section{Conselho Editorial}

Dr. Antônio Artur de Souza - Universidade Federal de Minas Gerais

Msc. Davilson Eduardo Andrade

Dra. Elizângela de Jesus Oliveira - Universidade Federal do Amazonas

Msc. Fabiane dos Santos

Dr. José Eduardo Ferreira Lopes - Universidade Federal de Uberlândia

Dr. Otaviano Francisco Neves - Pontifícia Universidade Católica de Minas Gerais

Dr. Luiz Cláudio de Lima - Universidade FUMEC

Dr. Nelson Ferreira Filho - Faculdades Kennedy

Ms. Valdiney Alves de Oliveira - Universidade Federal de Uberlândia

\begin{tabular}{|l} 
Dados Internacionais de Catalogação na Publicação (CIP) \\
Tomada de in (decisão) nas organizações/ \\
Elizângela de Jesus Oliveira, Rute Holanda \\
Lopes, Moisés Belchior, Marusca, Wisler - \\
Belo Horizonte - MG: Poisson, 2020 \\
Formato: PDF \\
ISBN: 978-65-86127-46-1 \\
DoI: 10.36229/978-65-86127-46-1 \\
Modo de acesso: World Wide Web \\
Inclui bibliografia \\
1. Administração 2. Gestão. 3. Processo \\
Decisório I. Oliveira, Elizângela de Jesus \\
II. Lopes, Rute Holanda, III. Belchior, \\
Moisés IV. Wisler, Marusca II. Título \\
CDD-658
\end{tabular}

O conteúdo do livro e seus dados em sua forma, correção e confiabilidade são de responsabilidade exclusiva dos seus respectivos autores.

www.poisson.com.br

contato@poisson.com.br 


\section{Prefácio}

O maior desafio das organizações é a tomada de decisão que por ser um processo amplo, envolve diversas áreas empresariais. Uma decisão deve está embasada em informações reais e válidas, para que o curso a ser seguido pelas empresas esteja alicerçado em uma vantagem estratégica competitiva e sustentável. Vale ressaltar ainda, que o processo de tomada de decisão é influenciado por variáveis subjetivas, como a percepção de mundo e vivência profissional do tomador de decisão, sendo assim faz se mister buscar conhecer qual o perfil do tomador de decisão e quais são as dimensões que prevalecem na tomada de decisão: a dimensão subjetiva ou a racional. Utilizando-se de uma linguagem simples, essa obra tem como finalidade apresentar conceitos relacionados à teoria da decisão e cases práticos que irão auxiliar os gestores nessa jornada de decidir qual o melhor caminho ou a melhor alternativa para as empresas adotarem. Assim, recomenda-se também essa obra aos discentes que buscam compreender e pesquisar sobre o processo de tomada de decisão empresarial. 


\section{Sumário}

Capítulo 01 - Tomada de decisão no contexto organizacional

Alice Nascimento Teixeira Rocha, Emilly Felipe de Lima e Lima, Cleisson Leite da Cunha,

Elizângela de Jesus Oliveira

DOI: 10.36229/978-65-86127-46-1.CAP.01

Capítulo 02 - Tomada de decisão sob risco e sob incerteza

lan dos Santos Soares, Willian de Souza Marques, Elizângela de Jesus Oliveira

DOI: 10.36229/978-65-86127-46-1.CAP.02

Capítulo 03 - Teoria dos Jogos e Processo Decisório

Gustavo Grana Ramos, Igor Viana dos Santos, Elizângela de Jesus Oliveira

DOI: 10.36229/978-65-86127-46-1.CAP.03

Capítulo 04 - Planejamento estratégico no processo de tomada de decisão

Carla Valéria Santos, Nediza Marques de Oliveira, Elizângela de Jesus Oliveira

DOI: 10.36229/978-65-86127-46-1.CAP.04

Capítulo 05 - Análise dos estilos de tomada de decisão de egressos dos cursos de engenharia

Hugo Glória Pantoja, Everton Jucelin Braz Gonçalves, Elizângela de Jesus Oliveira

DOI: 10.36229/978-65-86127-46-1.CAP.05

Capítulo 06 - Perspectiva da Gestão de Pessoas

Elizângela de Jesus Oliveira, Alice Nascimento Teixeira Rocha, Gleica Soyan B. Alves, Anderson Lincoln Vital.

DOI: 10.36229/978-65-86127-46-1.CAP.06

Capítulo 07 - Evolução do Conceito de Gestão de Pessoas

Afrânio Esquerdo Viana, Elizângela de Jesus Oliveira, Alice Nascimento Teixeira

Rocha, Gleica Soyan B. Alves, Anderson Lincoln Vital.

DOI: 10.36229/978-65-86127-46-1.CAP.07 


\section{CAPITULO Tomada de decisão no contexto organizacional}

Alice Nascimento Teixeira Rocha, Emilly Felipe de Lima e Lima, Cleisson Leite da Cunha, Elizângela de Jesus Oliveira

\section{INTRODUÇÃO}

O processo de tomada de decisão é um tema que vem sendo abordado desde muitas décadas, porém, por ser um processo que para seu desenvolvimento considera os aspectos envolvidos no contexto em que está inserido, ainda se faz relevante para estudos atuais, visto que depende de fatores que mudam ao longo do tempo. A cada dia o mercado se torna mais globalizado e competitivo, o que o torna também um ambiente bastante dinâmico, exigindo dos gestores mais agilidade e eficiência no processo decisório. Neste contexto, o tempo disponível para a tomada de decisão vem sendo reduzido continuamente, fazendo com que os gestores se deparem com problemas e conflitos na busca pela eficácia do processo de tomada de decisão, já que qualquer erro pode definir a vida ou morte da empresa no mercado.

A tomada de decisão é considerada por Wang (2004) como um processo cognitivo básico do comportamento humano, neste processo, dentre as alternativas disponíveis, apenas uma opção ou um curso de ações são selecionados (apud WIESIOLEK, 2014). Desta forma, a decisão adequada a ser tomada é aquela conexa à capacidade de escolher estratégias comportamentais incluídas em uma determinada realidade (SOARES et al., 2012). O processo decisório se faz presente no cotidiano de toda e qualquer organização, ele ocorre desde os níveis mais baixos, como o chão de fábrica, até os níveis superiores.

Diariamente nas empresas, uma quantidade elevada de decisões é tomada, as quais podem ser analisadas por administradores, gestores e outros trabalhadores. Estas decisões vão desde as mais simples até as mais complexas, podendo afetar minimamente o andamento do processo produtivo da organização ou afetar fatores relevantes como o posicionamento da empresa no mercado global, sua sobrevivência, estagnação ou expansão, como afirmam Bertocini et al. (2016). Os autores corroboram ainda, que decisões são tomadas por pessoas, que são influenciadas pelo meio em que vivem, incluindo as perspectivas, experiências e crenças de cada uma, o que torna o processo de tomada de decisão ainda mais complexo e delicado, pois não existe uma "decisão perfeita", mas apenas a busca pela eficácia do processo decisório por meio da escolha da melhor alternativa disponível em dado contexto.

Referente ao que é conhecido como tomada de decisão final, Baron (2008) afirma que é conduzida para a consecução de objetivos, podendo ser simples, contendo apenas um objetivo que contempla duas opções, sendo que há fortes indicativos de será melhor opção. Ou complexa, quando há uma maior diversidade de informações a serem selecionadas, o que gera uma maior quantidade de opções a seremavaliadas. 
A partir dos pressupostos discutidos, o objetivo deste capítulo é analisar a importância da tomada de decisões dentro do contexto estratégico das organizações. Este trabalho está estruturado em três partes: a primeira é esta introdução. A segunda é composta pela discussão teórica que fundamenta este trabalho, a terceira é um case da aplicação do assunto central desta pesquisa, e por fim as referências.

\section{A RELEVÂNCIA DA TOMADA DE DECISÃO NO CONTEXTO ORGANIZACIONAL}

A todo o momento as pessoas precisam lidar com diversas situações que exigem que seja tomada uma decisão, diante de problemas demasiadamente diferentes. Para conseguir se decidir as pessoas fazem uso de experiências passadas, valores e crenças, conhecimentos técnicos, habilidades, filosofias, entre outros, cada um desses fatores norteando a forma como a decisão é tomada. As diferentes formas de tomar uma decisão podem resultar no sucesso ou fracasso das pessoas que a tomam e daqueles que dependem deste processo, bem como no sucesso ou fracasso das organizações em que estas pessoas estão inseridas. Com a evolução da tecnologia e as recorrentes mudanças no mercado empresarial, as decisões tornam-se mais complexas nas organizações, exigindo do líder e dos colaboradores uma maior precisão na tomada de decisão (LIMA, 2012; OLIVEIRA, 2017).

Uma gama de profissionais, como empresários, gestores, engenheiros, empreendedores, administradores, e assim por diante, estão sempre enfrentando situações que apresentam um diversificado número de caminhos, dentre os quais é necessário escolher aquele que proporcione à organização o atingimento do seu potencial máximo. Para Marques (2018) um bom líder é aquele que é capaz de tomar decisões que gerem resultados positivos para a organização, para seus colaboradores de uma forma geral, e para si mesmo enquanto profissional. 0 autor ainda acrescenta que no que diz respeito a vida profissional do indivíduo, o poder de fazer a escolha certa é o que vai definir suas decisões e a forma como apresenta e sustenta suas convicções, desta forma fazer a escolha certa exige que a pessoa seja confiante, seja sincera com suas escolhas e alicerce-se em um conjunto de informações reais sobre a situação a ser decidida. Por isso, é importante que seja evitado protelar ou deixar as decisões para depois, visto que o atraso na decisão geralmente promove resultados negativos à organização.

\section{O PROCESSO DECISÓRIO NO DIA-A-DIA DAS ORGANIZAÇÕES}

\subsection{PROCESSO DECISÓRIO NA ÁREA DE MARKETING}

Uma organização frequentemente se encontra diante de problemas sérios de decisão, sendo que geralmente fica a cargo do líder resolver o problema, de modo que ele poderia analisar o problema e escolher a melhor alternativa de modo inteiramente informal. Entretanto, em uma organização, os problemas são muito mais amplos e complexos, envolvendo riscos e incertezas, por isso necessitam da opinião e participação de muitas pessoas, em diversos níveis funcionais. Diante disto, o processo de 
tomada de decisão em uma empresa ou organização deve ser estruturado e resolvido de maneira formal, sendo feito detalhada, consistente e transparentemente (LIMA, J. A., 2012; MARQUES, 2018). No marketing, não é diferente, pois também se considera fatores emocionais e aspectos intuitivos, além das informações que devem ser estratégicas e sistematizadas.

0 marketing é uma área do comércio que engloba todas as atividades envolvidas com a troca, sendo que tais atividades buscam a satisfação dos desejos e necessidades dos clientes, almejando alcançar os objetivos da empresa, considerando o ambiente de atuação e o impacto destas relações, conforme preconiza Las Casas (2011). Neste intento, no que corroboram os autores, é possível identificar que o marketing influência diretamente a tomada de decisão das empresas, pois o mesmo integra o processo administrativo, auxiliando o setor de vendas, além disso, pode ser utilizado como tática para a divulgação e fidelização de clientes. Assim, a área de marketing é considerada extremamente decisiva no processo de tomada de decisão, pois operacionaliza a visão da organização que é atender o cliente com o máximo de qualidade, menor tempo e menor custo possível.

\subsection{PROCESSO DECISÓRIO NA ÁREA DE PRODUÇÃO}

O setor produtivo em qualquer organização deve ser planejado adequadamente, esse planejamento é comumente chamado nas indústrias de programação da produção, a qual é realizada dentro de um horizonte de curto prazo que visa atender necessidades de produção pré-definidas (PORTO \& BANDEIRA 2006; TEIXEIRA JR, 2008). Tais necessidades se apresentam na forma de ordens, atendendo a um grande número de características específicas e restrições do ambiente. Na maioria das organizações, para a elaboração adequada deste planejamento, além de se considerar os diferentes produtos a serem produzidos e as inúmeras possibilidades de produção, é necessário considerar também as incertezas relacionadas, como por exemplo, qualidade dos produtos, quebras de máquina, manutenção de equipamentos e instalações, atrasos na entrega de matéria-prima, entre outros fatores (TEIXEIRA JR, 2008). Devido a isso, a forma como as decisões são tomadas na elaboração da programação da produção influencia fortemente os resultados obtidos pela organização, uma vez que são decididas características como, o balanceamento da carga de trabalho dos recursos, tempos em filas, disponibilidade de materiais, data de entrega, e assim por diante.

Uma organização em constante crescimento está sujeita a influência de variáveis internas e externas, atualmente o principal destes efeitos é a evolução tecnológica, pois somente a utilização da mão de obra humana não tem sido suficiente para atender às grandes demandas de produtos, o que acaba por contribuir para a não obtenção dos resultados esperados pelos gestores (MARTINS \& BONFADINI, 2015). Por isso, profissionais da área de produção têm recorrido a ferramentas e sistemas de apoio para tais processos, o que facilita o uso correto de informações, proporcionando controles mais eficazes e, o mais importante, fornecendo suporte à tomada de decisão. 
Independentemente do nível de serviço ou de produção da empresa, os sistemas de informação têm como maior objetivo auxiliar os processos de tomada de decisões na organização (REZENDE; ABREU, 2013). Neste contexto, o foco dos sistemas deve ser orientado para o segmento ou ramo da empresa, caso contrário os sistemas não serão capazes de atingir todo o seu potencial, mas atuariam somente como fatores secundários de apoio. Por exemplo, uma indústria deve ter sistemas de informação direcionados ao processo operacional, auxiliando principalmente nas áreas de produção e comercialização de seus produtos industrializados, ou seja, o principal intuito está relacionado com a qualidade, produtividade, rentabilidade e competitividade empresarial (MELO, 2006).

Para Teixeira Jr (2008) a tomada de decisão na elaboração da programação da produção tem como objetivo a adequação e sistematização do processo decisório às necessidades da organização, buscando fornecer as exigências de flexibilidade e efetividade impostas pelo ambiente produtivo, sem criar um distanciamento com o tomador de decisões, visto que a proximidade com o decisor representa um fator crucial para obter êxito na escolha da melhor alternativa, que é aquela que proporciona à empresa o atingimento do seu potencial máximo.

\subsection{PROCESSO DECISÓRIO NA ÁREA FINANCEIRA}

Quando se trata da gestão financeira nas organizações, a principal fonte de informações para os gestores é a contabilidade, pois ela protagoniza o processo de tomada de decisão (RODRIGUES et al., 2014). Entre os ramos da contabilidade, tem-se a contabilidade de custos, e sabe-se que o custo é o principal fator a ser considerado pela empresa em toda e qualquer decisão, já que este ramo da contabilidade tem elevada importância nos meios econômicos, contábeis e financeiros. A contabilidade originou-se da necessidade de avaliar os resultados nas indústrias e verificar o valor dos estoques, o que fez com que viesse a ser uma ferramenta imprescindível para controle e tomada de decisões. (MARION, 2008, p. 26)

As contínuas mudanças no mercado advindas dos mais variados fatores resultaram para as empresas em um ambiente complexo e arriscado em termos de decisão, ou seja, as questões financeiras torneiam as relações empresariais e ocupam grande parte das preocupações atuais das empresas (SILVA, 2012). A globalização financeira, a liberalização cambial e a influência de fatores externos compõem o cotidiano das empresas, visto que a análise das finanças no mundo moderno possui elevada relevância. Contudo, essa integração globalizada trouxe incertezas e dificuldades às decisões financeiras, pois essas decisões são tomadas nas organizações empresariais de forma contínua, inevitável e integradas ao cenário de desenvolvimento mundial (SILVEIRA et al, 2017).

Para Schultz (2018), a organização do capital de uma empresa é conexo a um bom plano financeiro, que é aquele que apresenta um fluxo de caixa eficiente e garante a capacidade de arcar com todos os custos e despesas necessários para manter as atividades da organização, sendo que a eficiência desse plano é diretamente dependente de seguras e pertinentes decisões. Por isso, a tomada de decisão no setor 
financeiro requer especial atenção, pois as atividades relacionadas à produção da organização necessitam de uma boa gestão financeira para serem mantidas.

Tomando-se como referência os pressupostos teóricos discutidos, é de fundamental importância que os gestores conheçam as teorias que embasam o processo decisório. Na próxima seção, discutiremos algumas teorias da decisão.

\section{TEORIAS DA DECISÃO}

\subsection{TEORIA DA UTILIDADE ESPERADA}

A Teoria da Utilidade Esperada é uma ferramenta teórica padrão muito utilizada para análise de custobenefício sob condições de risco. A teoria apresentou uma interpretação operacional da utilidade, até então considerada parâmetro de qualidade, além de viabilizar a modelagem da incerteza a partir de fundamentos sólidos, consolidando um caráter científico (CUSINATO, 2003; BUCHHOLZ e SCHYMURA, 2012).

A teoria da utilidade esperada, de Von Neumann e Morgenstein (1944), foi amplamente utilizada e aceita, e ainda é aplicada atualmente nos processos de tomada de decisão. No entanto, após a realização de muitos estudos do comportamento humano no ambiente de tomada de decisão, comprovou-se que o comportamento humano viola os princípios da teoria (BALDO, 2007).

\subsection{TEORIA DOS PROPECTOS}

Por serem psicólogos, os criadores da teoria do prospecto, Kahneman e Tversky (1979), estavam interessados em entender como os serem humanos são influenciados durante a tomada de decisão. A Teoria dos Prospectos surgiu para rebater a Teoria da Utilidade Esperada, que dominava como exemplo e modelo para tomada de decisões na época. A teoria sugere três aspectos principais: (i) as pessoas analisam suas recompensas e perdas comparados a um ponto neutro ou nulo; (ii) as pessoas avaliam possíveis resultados como ganhos ou perdas comparados a um ponto fixo de referência; (iii) as pessoas determinam suas escolhas com base em alterações no posicionamento dos ativos (KAHNEMAN e TVERSKY, 1979; SANTOS e BOTELHO, 2011; KRUGER et.al., 2018).

A Teoria dos Prospectos, considera seus resultados como ganhos e perdas, abandonando a visão de "riqueza" que se tem na Teoria da Utilidade Esperada. A partir da Teoria dos Prospectos, verifica-se que um decisor não necessariamente possui convicção total acerca da decisão escolhida por ele. Os autores da teoria buscaram, por meio dos seus experimentos, relevar este fato e romper essa visão de que, na tomada de decisão, há dominância e invariância (KAHNEMAN e TVERSKY, 1974, 1979; KRUGER et.al.,2018). 


\subsection{TEORIA DO CONJUNTO FUZZY}

A teoria do conjunto fuzzy foi proposta por Atanassov em 1986, e desde então vem ganhando espaço entre os acadêmicos e tem estado presente na grande maioria dos trabalhos relacionados a teorias de decisão e possui aplicações em problemas de tomada de decisão multicritério (ZHINAN, 2016).

De acordo com Gusmão et. al. (2018), a teoria de decisão fuzzy ou teoria dos conjuntos fuzzy é caracterizada por um conjunto de objetos de estudo e pela determinação dos valores de associação de cada objeto. Os valores de associação expressam o grau de compatibilidade entre o objeto e as características da coleção; podem assumir valores entre 0 (exclusão completa da coleção) e 1 (associação completa à coleção). De forma simplificada, um conjunto fuzzy é uma função que associa os elementos de um universo $\mathrm{U}$ ao intervalo $\mathrm{C}[0,1]$. Considerando $\mathrm{x}$ é um elemento do Universo $\mathrm{U}$ e $\mathrm{C}(\mathrm{x})$ o grau de associação correspondente, um conjunto fuzzy também por ser expressado com o conjunto de pares ordenados do tipo $\{\mathrm{x}, \mathrm{C}(\mathrm{x})\}$.

\subsection{TEORIA DA LACUNA DE INFORMAÇÃO}

De acordo com esta teoria, o tomador de decisão deve ser capaz de avaliar a eficácia de cada estratégia cogitada, determinar suas prioridades e avaliar a função objetivo. Em virtude disso, a teoria da lacuna de informação apresenta-se como uma ferramenta eficiente para a avaliação e comparação de estratégias aplicadas nos momentos de incerteza - busca maximizar o nível de resistência do sistema operacional contra a incerteza dentro da região segura. Simultaneamente, a teoria da lacuna de informação também procura resolver demais fatores que possam vir a limitar a extensão do conjunto de incertezas seguras (NAJAFI-GHALELOU, NOJAVAN e ZARE, 2017; MAJIDI, MOHAMMADI-IVATLOO e SOROUDI, 2019). A incerteza pode resultar em aspectos positivos que levam a custos operacionais mais baixos ou pode apresentar aspectos que levam a maiores custos de operação. A ferramenta da teoria da lacuna de informação trabalha com essas duas possibilidades conflitantes. Os resultados obtidos podem auxiliar o tomador de decisões na avaliação dos riscos e oportunidades e reconhecer prioridades de decisão (NAJAFI-GHALELOU, NOJAVAN e ZARE, 2017).

Diferentemente de outros métodos para modelagem de incerteza, a teoria da lacuna da informação não demanda uma grande quantidade de dados para modelagem da incerteza. Durante a exploração dos dados disponíveis, a ferramenta informa ao operador a respeito dos resultados que podem resultar da incerteza para direcionar tomada de decisões apropriadas e lógicas, mesmo que estas ainda possam ser seguras ou não (MAJIDI, MOHAMMADI-IVATLOO e SOROUDI, 2019). Em seguida, o método trabalha para tornar o desempenho do sistema imune ao parâmetro incerto, buscando manter o ponto operacional dentro da região segura e, deste modo, garantindo que o sistema não entre na região de risco. 


\subsection{TEORIA BAYESIANA}

A teoria bayesiana de decisão (ou Teoria de Decisão Bayesiana) tem sido amplamente aplicada em problemas não determinísticos em diferentes áreas, como engenharia, economia, negócios, marketing, avaliação de risco, política e entre outras áreas profissionais. A abordagem bayesiana tem sido usada para fins de filtragem, estimativa, pré-dicção e tem proporcionado muitos grandes benefícios para inúmeras organizações (MARHAMATI, 2018).

A teoria bayesiana é utilizada em casos de problemas mal estruturados e lida com a incerteza por meio de estudos em probabilidade. Dessa forma, se a incerteza de um teste for muito alta, isto pode ser corrigido ou amenizado por meio da teoria bayesiana com base no conhecimento prévio (MARHAMATI, 2018). Contudo, a teoria bayesiana necessita de valores exatos referentes a todos os parâmetros das funções de distribuição, não sendo tão eficaz quando não estão disponíveis os valores precisos para o cálculo em probabilidade. Segundo Shafer $(2015$, p. 1), os resultados fornecidos pela teoria bayesiana "devem ser interpretados como uma norma, um padrão de coerência e consistência que os tomadores de decisão devem se esforçar para alcançar".

Considerando-se as teorias de decisão discutidas, faz-se necessário ainda, conhecer as condições nas quais são delineados os processos decisórios. $\mathrm{Na}$ próxima seção, discorre-se sobre alguns fatores influenciadores da tomada de decisão.

\section{PROBLEMAS NA TOMADA DE DECISÃO}

\subsection{CLASSIFICAÇÃO DOS PROBLEMAS DE DECISÃO}

De acordo com Moreira (2013), os problemas de decisão são comumente rotulados segundo o grau de informação que temos disponível, envolvendo fatores como incerteza, consequências de alto risco, alternativas e questões interpessoais, podendo classificar-se em três possibilidades:

Decisão tomada sob certeza: quando se tem total conhecimento dos fatores e possíveis acontecimentos relacionados ao problema, através de fundamentação teórica e/ou experiências, ou ainda, quando considera-se o problema com baixa probabilidade de alteração, sendo improvável resultar em impactos negativos.

Decisão tomada sob risco: quando se tem conhecimento parcial dos fatores e possíveis acontecimentos relacionados ao problema, podendo atribuir probabilidades de ocorrência para cada caso, tendo em vista que cada possibilidade atribuída equivale a um determinado risco.

Decisão tomada sob incerteza: é o caso mais crítico, quando não se tem nenhum conhecimento dos fatores e acontecimentos relacionados ao problema, um evento considerado inédito, não sendo possível sequer a 
estipulação de probabilidades de ocorrência devido à falta de informação e alta possibilidade de alteração do conteúdo ligado ao mesmo.

Tomando-se como referência as diversas situações que influenciam as tomadas de decisão, faz-se necessário conhecer métodos que podem ser utilizados para solucionar alguns problemas. Na próxima seção, apresentam-se alguns métodos utilizados na resolução de problemas.

\subsection{MÉTODO DE RESOLUÇÃO DE PROBLEMAS}

Para Lapenda (2012), resolver problemas é parte do processo decisório e representa um processo sistemático que se concentra na análise de uma situação difícil com o intuito de encontrar a solução eficaz. Entretanto, fazer isso sem base em dados e fatos concretos pode ser extremamente prejudicial para qualquer negócio (MATHIAS, 2018), o que torna essencial o conhecimento das 5 fases do processo decisório e o entendimento na maneira como usá-las. São elas: identificação do problema; listagem de alternativas; avaliação e escolha; implementação da decisão e controle da decisão.

A 1ํ Fase faz uma definição cuidadosa de todo processo e seus respectivos riscos, tratando-os como divisores de água para uma tomada de decisão bem-sucedida, nos remetendo a questionamentos que nos levam ao caminho de soluções mais eficazes, podendo atacá-lo diretamente na raiz. Isso torna imprescindível o conhecimento absoluto da situação antes de qualquer tomada de decisão, visto que todo problema tem sua peculiaridade.

A 2을 Fase consiste na formulação de diversas probabilidades para resolução do problema, alinhadas aos seus respectivos riscos, visando o máximo de alternativas possíveis afim de encontrar uma solução ótima. As alternativas são avaliadas na $3^{\circ}$ Fase, através de critérios definidos pelos próprios responsáveis pela decisão. 0 principal objetivo da avaliação de alternativas é selecionar a melhor decisão possível entre as várias possibilidades disponíveis.

Na $4^{\circ}$ fase, acontece a tomada de decisão em si, na qual se fazem as escolhas que julgam ser viáveis, realizando uma comparação entre as alternativas e considerando-se uma série de fatores, o que irá influenciar na escolha final. Na 5o e última fase, monta-se um sistema de acompanhamento que identifica os desafios para a implementação bem-sucedida e desenvolve estratégias de controle de riscos, fazendo um monitoramento dos impactos causados pela escolha, garantindo que o problema seja realmente solucionado.

Mediante aos conceitos apresentados, conclui-se então que não existem escolhas perfeitas para resolução de problemas específicos, existem apenas decisões assertivas que se encaixam em determinadas situações. Dessa forma, o objetivo do estudo foi abordar a maneira na qual a decisão foi tomada e a solução selecionada, podendo utilizar os conhecimentos absorvidos em problemas das mais variáveis espécies, 
não se limitando a um roteiro previamente estruturado, mas optando por construir um caminho próprio para encontrar a solução ideal.

\section{CASE}

Tomada de decisão: Analisando o uso de sistemas de informação na empresa joagro ferragens, de Estrela/RS

Bárbara Martins

Gerson José Bonfadini

A empresa alvo deste estudo atua no ramo metalúrgico e oferece produtos para o confinamento do gado leiteiro e implementos agrícolas, localizada na cidade de Estrela/RS, no Vale do Taquari, sendo que os fornecedores de informações para esta pesquisa foram os gestores da área de produção da empresa.

Para a coleta de dados, inicialmente, os pesquisadores entraram em contato com os gestores responsáveis e comunicaram-lhes os procedimentos que seriam realizados, verificando suas disponibilidades para com a pesquisa. Conseguinte, foram realizadas entrevistas com os gestores da área de produção da empresa. E utilizando a pesquisa bibliográfica, observações e os resultados obtidos por meio das entrevistas, foram elaborados, fluxogramas verticais de processos que representavam as funções atuais da empresa com o intuito de atender aos objetivos do trabalho. Além disso, como auxílio à coleta de dados e informações, os autores elaboraram um quadro teórico que relaciona os objetivos específicos da pesquisa com os principais fatores a serem identificados para a elaboração das variáveis.

A partir deste quadro foi possível formular as variáveis relacionadas com o problema de pesquisa e os objetivos propostos às respostas que o estudo buscava. Desta forma, utilizando as variáveis como base para as entrevistas com os dois gestores da área de produção os dados necessários foram coletados e dúvidas ao longo da pesquisa foram esclarecidas, assim, foi realizada a elaboração dos fluxogramas e os processos atuais de gestão de produção da empresa foram analisados. 
Tabela 1-Quadro 1 - Quadro teórico para construção de variáveis

\begin{tabular}{|c|c|c|c|}
\hline Objetivo específico & Fundamentação & Autores & Variável (pergunta) \\
\hline $\begin{array}{l}\text { Descrever o fluxo de } \\
\text { informações utilizado na } \\
\text { tomada de decisão da área de } \\
\text { produção. }\end{array}$ & $\begin{array}{l}\text {-Fluxo das informações } \\
\text { nos processos; } \\
\text { - Fluxograma. }\end{array}$ & $\begin{array}{l}\text { - Beal (2012); } \\
\text { - Oliveira (2005); } \\
\text { - Slack, Chambers e } \\
\text { Johnston (2009). }\end{array}$ & $\begin{array}{l}\text { - Existem pessoas encarregadas para o } \\
\text { controle de qualidade do produto } \\
\text { acabado? } \\
\text { - Existe descrição formal de cada } \\
\text { processo da área de produção? }\end{array}$ \\
\hline $\begin{array}{l}\text { Identificar os sistemas de } \\
\text { informação que os gestores } \\
\text { da área de produção utilizam } \\
\text { em suas tomadas de decisão. }\end{array}$ & $\begin{array}{l}\text {-Sistemas de informação; } \\
\text { - Tipos de sistemas; } \\
\text { - Tomada de decisão. }\end{array}$ & $\begin{array}{l}\text {-Rezende e Abreu (2013); } \\
\text {-Rosini e Palmisano } \\
\text { (2012); } \\
\text {-Shimizu (2001). - }\end{array}$ & $\begin{array}{l}\text { Existe algum sistema de informação } \\
\text { que sirva de apoio para sua tomada de } \\
\text { decisão? Se sim, quais? Atendem a } \\
\text { suas necessidades? }\end{array}$ \\
\hline $\begin{array}{l}\text { Apontar as principais } \\
\text { virtudes e falhas relativas às } \\
\text { informações utilizadas nos } \\
\text { processos de decisão da área } \\
\text { de produção. }\end{array}$ & $\begin{array}{l}\text { - Qualidade da } \\
\text { informação }\end{array}$ & $\begin{array}{l}\text {-Cândido, Valentim e } \\
\text { Contani (2005); } \\
\text {-Oleto (2006); } \\
\text {-Silva (2008). }\end{array}$ & $\begin{array}{l}\text { - Quais as tarefas que, no seu } \\
\text { entender, apresentam maiores } \\
\text { dificuldades para sua tomada de } \\
\text { decisão? Justifique. } \\
\text { - Existe adequada autonomia paraas } \\
\text { tomadas de decisão e realização das } \\
\text { tarefas no setor que você controla? } \\
\text { Justifique. } \\
\text { - No seu entender, quais os problemas } \\
\text { ou falhas que aparecem no processo } \\
\text { de recebimento, troca ou tratamento } \\
\text { de informações? } \\
\text { - Cite as virtudes existentes relativas } \\
\text { às informações que utiliza nos } \\
\text { processos de tomada de decisão }\end{array}$ \\
\hline $\begin{array}{l}\text { Propor melhorias ao processo } \\
\text { de tomada de decisão na } \\
\text { gestão da área de produção } \\
\text { da empresa analisada. }\end{array}$ & $\begin{array}{l}\text {-Racionalização; } \\
\text {-Padronização; } \\
\text {-Técnicas. }\end{array}$ & $\begin{array}{l}\text { - Carreira (2009); } \\
\text {-Chiavenato (2010); } \\
\text {-Wanzeler et al. (2010) }\end{array}$ & $\begin{array}{l}\text { - Existem problemas decorrentes da } \\
\text { falta de definição, delimitação, } \\
\text { superposição ou duplicação de } \\
\text { funções? Se sim, quais? - Existem } \\
\text { manuais ou formulários padronizados } \\
\text { que sirvam de apoio para suas funções } \\
\text { e também para os demais } \\
\text { colaboradores da área? Se sim, quais? } \\
\text { - Existe necessidade, no seu entender, } \\
\text { de se criarem ou expandirem novos } \\
\text { setores ou atividades? Ou } \\
\text { desmembrar setores ou atividades } \\
\text { existentes? Quais? }\end{array}$ \\
\hline
\end{tabular}

Fonte: MARTINS; BONFADINI, 2015.

Os fluxogramas representam os processos da área de produção da organização, divididos em: PCP, Manufatura, Estoque e Expedição. Os autores do trabalho ressaltam que não havia uma descrição formal desses processos na empresa, por isso a descrição de cada fluxograma agrega considerável valor à empresa, visto que para uma tomada de decisão eficaz é necessário identificar as etapas que exigem decisão por parte dos gestores.

Uma vez que a análise do processo de gestão da empresa se iniciou com a entrevista, as respostas obtidas foram usadas principalmente para alcançar os objetivos específicos da pesquisa. Estes podem resumidos em quatro: (i) descrever o fluxo de informações utilizado na tomada de decisão da área de produção, (ii) identificar os sistemas de informação que os gestores da área de produção utilizam em suas tomadas de decisão, (iii) apontar as principais virtudes e falhas relativas às informações utilizadas nos processos de decisão da área de produção e (iv) propor melhorias ao processo de tomada de decisão na gestão da área de produção da empresa analisada. 
Figura 1 - fluxograma elaborado para o processo de PCP

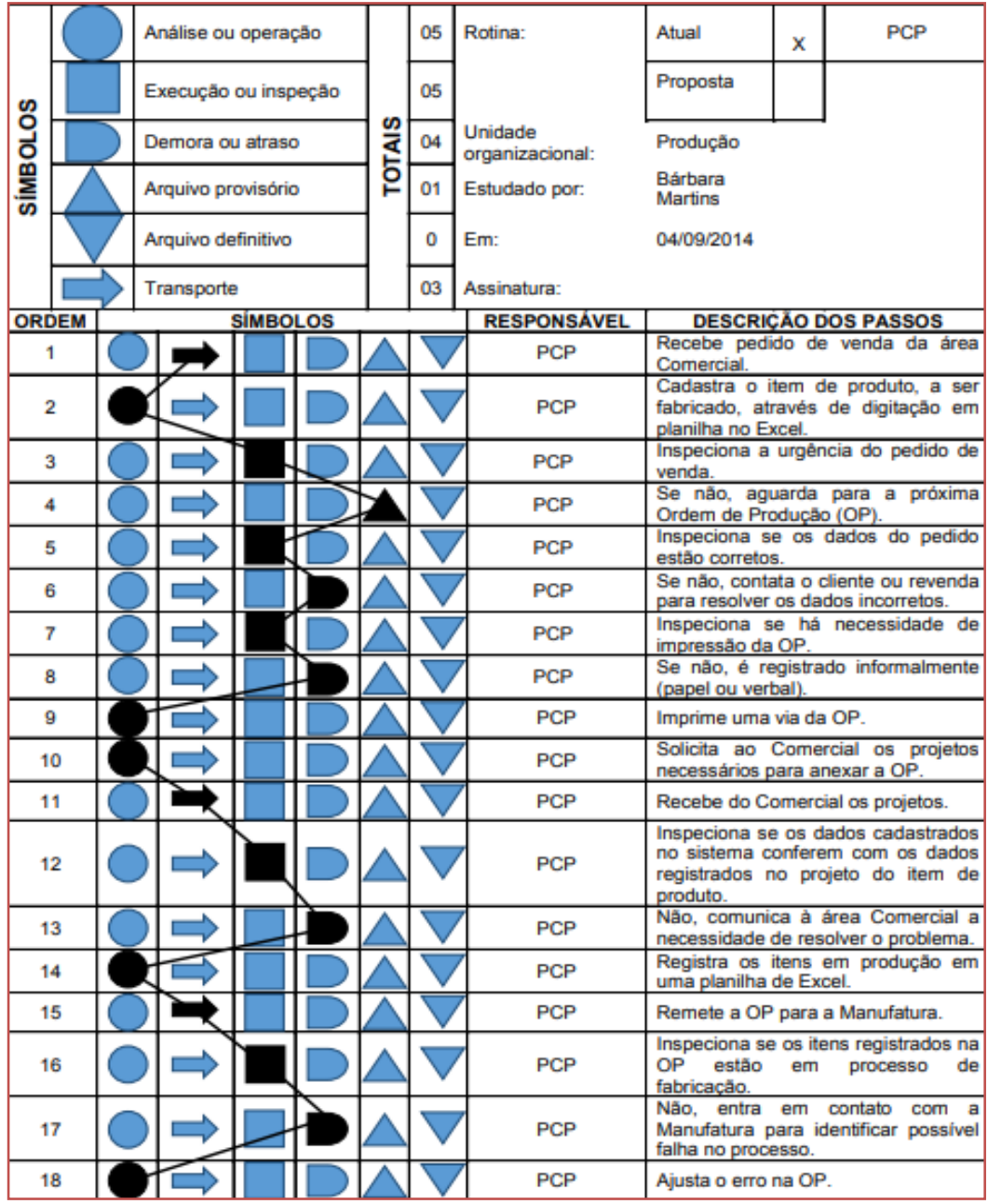

Fonte: MARTINS; BONFADINI, 2015.

Além do fluxograma de PCP apresentado, foram elaborados os fluxogramas de manufatura, estoque e expedição, totalizando quatro fluxogramas, cada um apresentando cinco, dois, quatro e três passos, respectivamente, em que ocorrem a tomada de decisão. No total, são quatorze etapas referentes a tomada de decisão identificados nos processos da organização.

Verificou-se, por meio da pesquisa, a importância do tomador de decisões para a empresa, uma vez que a empresa atua há 22 anos atendendo os produtores rurais e demais consumidores. Contudo, atualmente a empresa apresenta uma rotina de trabalho mais complexa, exigindo uma sofisticação em seus processos organizacionais, o que demanda um maior controle global dos processos, visando ter um bom desempenho frente à concorrência e alcance de lucros satisfatórios.

Por questões de simplificação do estudo, o foco do trabalho foi direcionado ao setor de produção. Com base nas entrevistas, observações e fluxogramas, verificou-se a importância de implementar um sistema de informação estruturado e direcionado aos objetivos da organização. A partir disso, os resultados 
obtidos foram disponibilizados para os gestores da empresa para que fossem percebidos, ponderados e implementados como melhorias nos processos.

\section{REFERÊNCIAS}

[1] BARON, Jonathan. Thinking and deciding (4. ed.). New York: Cambridge University, 2008.

[2] BEAL, Adriana. Gestão estratégica da informação: Como transformar a informação e a tecnologia da informação em fatores de crescimento e de alto desempenho nas organizações. São Paulo: Atlas, 2012.

[3] BERTOCINI, Cristine; BRITO, Adriana; LEME, Elisangela; SILVA, Ismael; SILVA; Thiago Ferreira; PERRI, Ricardo Alves. PROCESSO DECISÓRIO: A TOMADA DE DECISÃO. São Paulo: Faculdade de Ciências Jurídicas e Gerenciais, 2016.

[4] CÂNDIDO, Carlos Aparecido; VALENTIM, Marta Lígia Pomim; CONTANI, Miguel Luiz. Gestão estratégica da informação: Semiótica aplicada ao processo de tomada de decisão. Revista de Ciência da Informação. v. 6, n. 3 jun/2005. Disponível em: <http://www.dgz.org.br/jun05/Art_03.htm>. Acesso em: 07 maio 2014.

[5] CARREIRA, Dorival. Organização, sistemas e métodos: ferramentas para racionalizar as rotinas de trabalho e a estrutura organizacional da empresa. São Paulo: Saraiva, 2009.

[6] CHIAVENATO, Idalberto. Iniciação a sistemas, organização e métodos: SO\&M. Barueri, SP: Manole, 2010. Ebook. Disponível em: <http://univates.bv3.digitalpages.com.br/users/publications/9788520430804/ pages/_1.>. Acesso em: 16 ago. 2014.

[7] LAPENDA, José. Planejamento estratégico e processo decisório. Disponível em: https://administradores.com.br/artigos/planejamento-estrategico-e-processo-decisorio Acesso em: 31/07/2019

[8] LAS CASAS, A. Administração de vendas. 8ª Ed. São Paulo: Atlas, 2011.

[9] LIMA, Josimara Alves. LIDERANÇA E TOMADA DE DECISÃO NA ORGANIZAÇÃO. 2012. Trabalho de Conclusão de Curso (Especialização MBA em Administração Estratégica e Financeira) - Universidade Do Oeste De Santa Catarina, Santa Catarina, 2012.

[10] MARION, José Carlos. Contabilidade Básica. 8 ed. São Paulo: Atlas 2008.

[11] MARQUES, J. R. A importância da tomada de decisões nas organizações. Instituto Brasileiro de Coaching, 2018. Disponível em <https://www.ibccoaching.com.br/portal/a-importancia-da-tomada-de-decisoes-nasorganizacoes/> Acessado em: 28/07/2019.

[12] MARTINS, Bárbara; BONFADINI, Gerson José. TOMADA DE DECISÃO: ANALISANDO O USO DE SISTEMAS DE INFORMAÇÃO NA EMPRESA JOAGRO FERRAGENS, DE ESTRELA/RS. Rio Grande do Sul: Revista Destaques Acadêmicos, 2015.

[13] MATHIAS, Lucas. Descubra quais são as 5 etapas do processo de tomada de decisão. Disponível em: https://mindminers.com/blog/etapas-processo-tomada-decisao/amp/ Acesso em: 31/07/2019

[14] MOREIRA, Daniel Augusto. Pesquisa Operacional. 2 ed. Revisado e atualizado - São Paulo: Cengage Learning, 2013.

[15] MORITZ, Gilberto de Oliveira; PEREIRA, Maurício Fernandes. Processo Decisório - 2 ed. Revisado e atualizado - Florianópolis: Departamento de Ciências da Administração/UFSC, 2012. 
[16] OLETO, Ronaldo Ronan. Percepção da qualidade da informação. UFMG, 2006. Disponível em: <http:// www.scielo.br/pdf/ci/v35n1/v35n1a07.pdf>. Acesso em: 22 jun. 2014.

[17] OLIVEIRA, Djalma de Pinho Rebouças de. Sistemas, organizações e métodos: Uma abordagem gerencial. 15. ed. São Paulo: Atlas, 2005.

[18] OLIVEIRA, Hugo Leonardo de Moura. Diga-me como tu és que te direi como geres: a influência da personalidade na tomada de decisão. 2017. Trabalho de Conclusão de Curso (M.Sc em Administração Pública) Programa de Pós-Graduação em Administração Pública em Rede Nacional, Minas Gerais, 2017.

[19] PORTO, M. A. G; BANDEIRA, A. O processo decisório nas organizações. São Paulo: XIII SIMPEP, 2006

[20] REZENDE, Denis Alcides; ABREU, Aline França. Tecnologia da informação aplicada a sistemas de informação empresariais: o papel estratégico da informação e dos sistemas de informação nas empresas. 9. ed. São Paulo: Atlas, 2013.

[21] REZENDE, Denis Alcides; ABREU, Aline França. Tecnologia da informação aplicada a sistemas de informação empresariais: 0 papel estratégico da informação e dos sistemas de informação nas empresas. 9. ed. São Paulo: Atlas, 2013.

[22] RODRIGUES, J. L. K.; COELHO, F. A.; SILVA, T. M. D. Processo de tomada de decisão na gestão financeira em empresas de construção civil: um estudo caso. Teresina: Revista FSA, 2014.

[23] ROSINI, Alessandro Marco; PALMISANO, Angelo. Administração de sistemas de informação e a gestão do conhecimento. 2. ed. São Paulo: Cengage Learning, 2012.

[24] SCHULTZ, Félix. Plano financeiro da empresa: como melhorar a tomada de decisões? . 2018. Disponível em <https://bomcontrole.com.br/plano-financeiro-da-empresa-como-melhorar-a-tomada-de-decisoes/> Acessado em: $30 / 07 / 10$

[25] SHIMIZU, Tamio. Decisão nas organizações: Introdução aos problemas de decisão encontrados nas organizações e nos sistemas de apoio à decisão. São Paulo: Atlas, 2001.

[26] SILVA, F. P. M. Tomada de decisão financeira: aplicando o processo orçamentário. Revista Administração em Diálogo, Uberlândia, Vol.14, n.3, Set/Out/Nov/Dez 2012.

[27] SILVA, Reinaldo 0. da. Teorias da administração. São Paulo: Pearson Prentice Hall, 2008. E-book. Disponível em: <http://univates.bv3.digitalpages.com.br/users/publications/9788576050902/pages/_1>. Acesso em: 22 jun. 2014 .

[28] SILVEIRA, V. C.; BARBOSA, T. S.; MONTEIRO A. N.; EDUARDO A. S.; RIBEIRO, J. S. Estudo da tomada de decisões financeiras a partir das publicações científicas nos últimos 10 anos. Mato Grosso do Sul: I Encontro Internacional de Gestão, Desenvolvimento e Inovação, 2017.

[29] SLACK, Nigel; CHAMBERS, Stuart; JOHNSTON, Robert. Administração da produção. 3. ed. São Paulo: Atlas, 2009.

[30] SOARES, J. M. Stress-induced changes in humam decision-making are reversible. Transl Psychiatry, v .2, n .7, p e131, 2012.

[31] TEIXEIRA JR, R. F. Estudo e Sistematização do Processo Decisório para Elaboração da Programação da Produção em Indústrias. Rio de Janeiro: XXVIII Encontro Nacional De Engenharia De Produção, 2008.

[32] WEISIOLEK, Carine Carolina. ENVELHECIMENTO NORMAL E TOMADA DE DECISÃO: Uma avaliação estrutural da circuitaria envolvida. 2014. Tese (Doutorado em Neuropsiaquiatria e Ciências do Comportamento) - 
Programa de Pós-Graduação em Neuropsiaquiatria e Ciências do Comportamento, Universidade Federal de Pernambuco, Pernambuco, 2014.

[33] WANZELER, Marítiza dos Santos et al. Padronização de processos em uma empresa do setor moveleiro: um estudo de caso. UEPA. São Paulo, 2010. Disponível em: <http://www.abepro.org.br/biblioteca/ enegep2010_tn_stp_113_745_16460.pdf>. Acesso em: 17 ago. 2014.

[34] CUSINATO, R. T. Teoria da decisão sob incerteza e a hipótese da utilidade esperada: Conceitos analíticos e paradoxos. Programa de Pós-graduação em Economia. Porto Alegre - RS, 2003.

[35] BUCHHOLZ, W. SCHYMURA, M. Expected utility theory and the tyranny of catastrophic risks. Ecological Economics. Alemanha, 2012.

[36] BALDO, D. Biomassas nas anomalias da teoria da utilizade esperada. Programa de Pós-graduação em Economia. Florianópolis - SC, 2007.

[37] KRUGER, S. D. et.al. Processo decisório sob efeito de preferências: aversão e exposição ao risco. Revista Contemporânea de Contabilidade. Florianópolis - SC, 2018.

[38] KAHNEMAN, D.; TVERSKY, A. Prospect theory: An analysis of decisions under risk. Econometrica, v. 47, p. 263-291, 1979.

[39] SANTOS, J. H. F.; BOTELHO, D. Análise comparativa de preços: Variáveis influentes na percepção de vantagem de compra. RAM - Revista de Administração da Mackenzie, v. 12, n.2, p. 61-79, 2011.

[40] ZHINAN, H. Novel Intuitionistic Fuzzy Decision Making Models in the Framework of Decision Field Theory. Information Fusion. China, 2016.

[41] GUSMÃO, A. P. H. et.al. Cyber security risk analysis model using fault tree analysis and fuzzy decision theory. International Journal of Information Management. Recife, 2018.

[42] NAJAFI-GHALELOU, A., NOJAVAN, S., ZARE, K. Robust thermal and electrical management of smart home using information gap decision theory. Applied Thermal Engineering. Irã, 2017.

[43] MAJIDI, M., MOHAMMADI-IVATLO0, B., SOROUDI, A. Application of information gap decision theory in practical energy problems: A comprehensive review. Applied Energy. Irã, 2019.

[44] MARHAMATI, N. et.al. Integration of Z-numbers and Bayesian Decision Theory: A Hybrid Approach to Decision Making under Uncertainty and Imprecision. Applied Soft Computing. Estados Unidos, 2018.

[45] SHAFER, G. Constructive decision theory. International Journal of Approximate Reasoning. Estados Unidos, 2015. 


\section{CAPITULO Tomada de decisão sob risco e sob incerteza \\ Ian dos Santos Soares, Willian de Souza Marques, Elizângela de Jesus \\ Oliveira}

\section{INTRODUÇÃO}

A tomada de decisão faz parte da rotina do ser humano, essas escolhas podem agregar um alto grau de complexidade para a resolução de problemas ou serem tão simplórias quanto escolher qual gravata usar. Loken (2007) afirma que as atividades de julgamento e escolhas realizadas pelas pessoas estão relacionadas aos seus valores, crenças e objetivos, mas com um único propósito, alcançar aquilo que desejam.

A complexidade do processo decisório vai muita além da mensuração do problema, envolve a forma como as informações foram adquiridas, quais os critérios para a avaliação e o custo das alternativas criadas para a solução do problema. (LOBLER, et al., 2019). De acordo com Rodrigues (2009), grande parte das decisões tomadas no ambiente organizacional é de caráter estratégico. Decisões estratégicas são aquelas consideradas mais complexas, pois a incerteza, os recursos dispostos e os riscos são maiores.

Diante disso, percebe-se que as decisões podem ser moldadas a partir do contexto em que se encontra inserido o decisor, levando-se em consideração a situação, os fatores do ambiente e os critérios subjetivos comportamentais (DOROW, 2012; MAJOLA \& VIEIRA, 2006). Desse modo, a natureza da decisão, muitas das vezes pode está vinculada às condições de riscos e incertezas característicos de um processo decisório, como por exemplo, quando se depara com o desenvolvimento de uma determinada atividade inovadora e disruptiva. Exemplifica-se também, quando são tomadas decisões de investimentos financeiros que ocorrem em muitas da vezes sob circunstâncias inusitadas ou horizonte de tempos curtos (LOPEZ, 2017;ANTONIO, 2002). Partindo dessas reflexões teóricas, surge-se a pergunta: Como é possível diferenciar as decisões tomadas em situações de riscos em relação às tomadas diante da incerteza?

A maioria dos julgamentos do nosso cotidiano é realizada perante a incerteza, como por exemplo, dirigir um carro ou realizar um diagnóstico médico, visto que o julgador desconhece a condição sob a qual ele não tem a informação necessária para atribuir probabilidades para os resultados das soluções alternativas, diante do qual necessita adivinhar eventos que podem acontecer a qualquer momento. Por outro lado em relação às decisões de risco, o decisor possui o conhecimento no que diz respeito às probabilidades associadas aos resultados. Um exemplo seria a execução de uma cirurgia, onde o cirurgião precisa conhece as probabilidades de sucesso baseadas em estatísticas (PINTO, 2016; TONETTO, 2006). 
A partir disso, o objetivo deste capítulo visa analisar o processo decisório de ambientes empresariais, com o intuito de demonstrar as características na tomada de decisão em um cenário de riscos e incertezas. Dessa forma, este capítulo se encontra organizado da seguinte forma: esta introdução, e seguindo-se posteriormente com uma revisão teórica na qual demonstra-se a visão organizacional a respeito de decisões tomadas sob riscos e incertezas. Por último, apresenta-se um case com a finalidade de avaliar a viabilidade econômica na produção de cana de açúcar na região de Jaú/SP e seguem-se com as referências.

\section{TOMADA DE (IN) DECISÃO}

Decidir qual é a melhor alternativa e achar a solução ideal para determinado problema, está diretamente relacionado à análise dos benefícios e dos prejuízos que cada escolha proporcionará. De acordo com Penhalbel (2018), a capacidade de tomar decisões é extremamente importante, pois ela se caracteriza como a principal ferramenta utilizada para lidar com as oportunidades, os desafios, as incertezas e as consequências, sejam elas boas ou más.

Em trabalho Hammond et al. (1999), afirma que poucas são as pessoas que, em alguma parte da vida, são instruídos á tomar decisões melhorando assim a qualidade de vida, alcançando os objetivos, reduzindo desperdícios de tempo e dinheiro, sendo que a grande maioria são obrigados a aprender com a experiência.

\section{CONCEITO DE INCERTEZA NO PROCESSO DECISÓRIO}

Adner (2006) retratou o conceito de incerteza como forma de tornar mais evidente a interdependência entre fatores no processo de criação e captura de valor, a competição e a cooperação construindo um ecossistema. Porém Gomes (2013) afirma que a evolução dos conceitos de incerteza tende a serem amplos e, em alguns casos, ambíguos, falhando em discernir as diferentes dimensões envolvidas e em descrever de modo mais compreensivo a incerteza.

O conceito de incerteza é bem vasto e difundido, o quadro abaixo traz alguns autores e suas visões a respeito desse tema.

Quadro 1: Definições de incerteza

\begin{tabular}{|l|l|}
\hline $\begin{array}{l}\text { Rogerio } \\
\text { Andrade } \\
(2011)\end{array}$ & $\begin{array}{l}\text { Em um ambiente que envolve valores, a incerteza é uma situação expressa por valores } \\
\text { indeterminados e não quantificáveis, isto é, refere-se a uma situação de "probabilidade } \\
\text { numericamente imensurável". }\end{array}$ \\
\hline $\begin{array}{l}\text { Danilo Sarti } \\
(2013)\end{array}$ & $\begin{array}{l}\text { O conceito mais popular de incerteza encontrado é de estado ou caráter do que é incerto falta de } \\
\text { certeza, dúvida, hesitação, indecisão. Embora generalista essa noção informal seja bastante útil e } \\
\text { eficaz quando bem utilizada. }\end{array}$ \\
\hline $\begin{array}{l}\text { Esther Zheng } \\
(2016)\end{array}$ & $\begin{array}{l}\text { Incerteza pode ser definida como uma situação onde não existe uma compreensão única e completa } \\
\text { do sistema a ser gerenciado. }\end{array}$ \\
\hline $\begin{array}{l}\text { Jéssica Costa } \\
(2017)\end{array}$ & $\begin{array}{l}\text { A incerteza é a incapacidade para determinar o sentido dos eventos relacionados com o problema que } \\
\text { ocorrem quando quem toma as decisões é incapaz de atribuir valor definitivo a objetos ou eventos } \\
\text { e/ou é incapaz de prever os resultados com precisão. }\end{array}$ \\
\hline
\end{tabular}

Fonte: Próprio autor 


\section{TOMADA DE DECISÃO SOB INCERTEZA OU SOB RISCO}

0 processo decisório para a solução de determinado problema envolve quatro subproblemas: enumerar as alternativas e os objetivos, medindo o benefício de cada alternativa; encontrar uma maneira de combinar múltiplos objetivos; analisar a alternativa que apresenta a melhor solução e trataras incertezas nos resultados sobre todas as alternativas (BRACARENSE; SANTOS; MAYERLE, 2013).

Em sua tese, Kikuti (2008) esclarece que em problemas de decisão sob risco, cada ação leva a um estado específico do conjunto de possíveis estados, sendo que cada estado ocorre com uma probabilidade conhecida. Já em problemas de decisão sob incerteza, cada ação leva a um estado especifico do conjunto de possíveis estados, porém, a probabilidade dos estados é desconhecida ou imprecisa.

\section{CONTRIBUIÇÕES - CASE}

Minarelli, et al (2016) em seu estudo, propôs analisar as condições de risco da tomada de decisão no investimento dos fornecedores para a produção da cana de açúcar na região Jaú/SP. Em vista disso, ele apresenta um modelo de análise, no qual são incluídas as incertezas em que o investimento proporciona, como política interna, produtividade, e a qualidade da matéria prima. São discutidas ainda, informações significativas relacionadas aos fornecedores para a comparação com vários outros projetos de investimento, com a finalidade da tomada de decisão ser mais assertiva.

Um fator analisado são os indicadores econômicos e que envolve uma avaliação da viabilidade econômica da produção, dos custos de produção da cana de açúcar, das condições do fornecedor. Realizou-se ainda, uma análise da sensibilidade das variáveis críticas (política interna, produtividade e a qualidade da matéria prima) relacionadas aos indicadores financeiros, com o objetivo de visualizar os seus percentis de risco, para o modelo de investimento proposto. Dessa forma, deu-se a criação de cenários econômicos, e por fim, o mapeamento de risco que permitiu identificar os níveis de rentabilidade associados ao risco, para os investidores interessados em fornecer a cana de açúcar.

Com isso, observou-se por meio da análise de sensibilidade que o preço pago ao fornecedor causa o maior impacto sobre a rentabilidade, quando comparada com a produtividade e qualidade da matéria prima. Observou-se ainda que os preços sofrem influência da conjuntura econômica internacional e da estabilidade política do Brasil. Por outro lado, a produtividade e a qualidade da matéria prima representam menor grau de interferência na rentabilidade, pois dependem de fatores ambientais e do manejo adequado da cultura pelo fornecedor de cana de açúcar.

De acordo com os resultados do estudo, foi visto que o fornecimento de cana de açúcar é dado como uma atividade de alto risco, em relação ao preço pago pelos fornecedores. Desta forma como forma de reduzir os custos, foi proposto a formação de condomínios agrícolas, e também a possibilidade de estabelecer 
garantias para o fornecedor, com a finalidade de redução dos riscos na produção de cana de açúcar na região Jaú/SP.

\section{REFERÊNCIAS}

[1] ADNER, R. (2006). MATCH YOUR INNOVATION STRATEGY TO YOUR INNOVATION ECOSYSTEM. Harvard Business Review, Vol. 84, n. 4, p. 98.

[2] ANDRADE, Rogerio P. de. A CONSTRUÇÃO DO CONCEITO DE INCERTEZA: UMA COMPARAÇÃO DAS CONTRIBUIÇÕES DE KNIGHT, KEYNES, SHACKLE E DAVIDSON. Nova Economia, Belo Horizonte, mai- ago.2011.

[3] ANTONIO, C. B. J. AVALIAÇÃO ECONÔMICA DE EMPRESAS SOB CONDIÇÃO DE RISCO E INCERTEZAO: caso das Empresas de Internet. Tese (Doutorado em Economia)- Faculdade de Ciências Econômicas, Universidade Federal Do Rio Grande Do Sul. Porto Alegre, 2002.

[4] BRACARENSE, JOÃO CANDIDO; SANTOS, CÁRLITON VIEIRA; MAYERLE, SÉRGIO FERNANDO. TOMADA DE DECISÃO SOB CONDIÇÕES DE RISCO E INCERTEZA: UMA APLICAÇÃO DA LÓGICA FUZZY À BOVINOCULTURA DE CORTE DA REGIÃO SERRANA DE SANTA CATARINA, Teoria e Evidência Econômica. n.49, p. 73-101, Jul- Dez - 2013.

[5] COSTA, J. AS DEMÊNCIAS NA PERSPECTIVA DO FAMILIAR À LUZ DA TEORIA DAS INCERTEZAS DE MISHEL. Tese (Doutorado em Ciências e Tecnologias da Saúde) - Faculdade de Ceilândia, Universidade de Brasília. Brasília, 2017.

[6] DOROW, A. HEURÍSTICA DA ANCORAGEM NA ESTIMATIVA DE PREÇOS DE IMÓVEIS POR CORRETORES PROFISSIONAIS. Tese (Doutorado em Contabilidade) - Universidade Federal de Santa Catarina. Florianópolis, 2012.

[7] GOMES, L. A. V. CORRIDA MALUCA EM TERRITÓRIOS DESCONHECIDOS: COMO EMPREENDEDORES GERENCIAM INCERTEZAS INDIVIDUAIS E COLETIVAS EM ECOSSISTEMAS EMPREENDEDORES. Tese (Doutorado em Engenharia de Produção) - Escola Politécnica da Universidade de São Paulo. São Paulo, 2013.

[8] HAMmOND, J. S., Keeney, R. L. \& Raiffa, H. (1999) SMART CHOICES: A PRACTICAL GUIDE TO MAKING BETTER DECISIONS, Harvard Business School Press.

[9] KIKUTI, D. TOMADA DE DECISÃO SEQUENCIAL COM PREFERÊNCIAS PARCIALMENTE ORDENADASL. Tese (Doutorado em Engenharia de Controle e Automação Mecânica) - Escola Politécnica, Universidade De São Paulo, São Paulo, 2008.

[10] LÖBLER, M. L.; REIS, E.;NISHI, J. M.;TAGLIAPIETRA, R. D. INVENTÁRIO DE ESTILOS DE TOMADA DE DECISÃO: VALIDAÇÃO DE INSTRUMENTO NO CONTEXTO BRASILEIRO, Revista de Administração da UNIMEP. v.17, n.1, Janeiro- Abril - 2019.

[11] LOKEN, E. USE OF MULTICRITERIA DECISION ANALYSIS METHODS FOR ENERGY PLANNING PROBLEMS. Renewable \& Sustainable Energy Reviews, v. 11, n. 7, p. 1584-1595, 2007.

[12] LOPEZ, C. FATORES PSICONEUROENDÓCRINOS ENVOLVIDOS NO PROCESSO DE TOMADA DE DECISÃO SOB RISCO EM HOMENS ADULTOS JOVENS. Tese (Doutorado em Psicobiologia). Universidade Federal do Rio Grande do Norte. Natal, 2017. 
[13] MAJOLA, A.; VIEIRA, K. TOMADA DE DECISÃO EM AMBIENTE DE RISCO: UMA AVALIAÇÃO SOB A ÓTICA COMPORTAMENTAL. REAd - Revista Eletrônica de Administração, v.12, n.1, p. 114-140, Porto Alegre, 2006.

[14] MINARELLI, P. H. et al. TOMADA DE DECISÃO NA PRODUÇÃO DE CANA DE AÇÚCAR PELOS FORNECEDORES NA REGIÃO DE JAÚ-SP, SOB CONDIÇÕES DE RISCO. Tese (Doutorado em Agronomia) - Faculdade de Ciências Agronômicas, UNESP. Botucatu. 2016.

[15] PENHALBEL, Viviane Bezerra Menezes. DECISÃO SOB INCERTEZA NA EVOLUÇÃO DAS STARTUPS: UM PROCESSO SEQUENCIAL ENVOLVENDO RACIONALIDADE E INTUIÇÃO. Dissertação (Mestrado em Ciências) Faculdade De Economia, Administração E Contabilidade, Departamento De Administração, São Paulo, 2018.

[16] PINTO, M. S. ANALISE DE RISCO NA FORMAÇÃO DE DECISÕES DE PRÉ-DESPACHO EM SISTEMAS COM ELEVADA PENETRAÇÃO EÓLICA. Tese (Doutorado em Engenharia Elétrica). Universidade Federal do Maranhão. São Luis, 2016.

[17] RODRIGUES, Fabiano. DINÂMICA DO PROCESSO DECISÓRIO EM EQUIPE: ANÁLISE TEMPORAL AMBIENTAL. Tese (Doutorado em Administração) - Faculdade de Economia, Administração e Contabilidade, Universidade de São Paulo. São Paulo, 2009.

[18] SARTI, Danilo Augusto. GERENCIAMENTO DE INCERTEZAS POR ANÁLISE DE DECISÕES: APLICAÇÕES À OTIMIZAÇÃO DA PRODUÇÃO E DEMANDAS INCERTAS. Dissertação (Mestrado em Ciências) - Escola Superior De Agricultura, Universidade De São Paulo, São Paulo, 2013.

[19] TONETTO, L. M., et al. O PAPEL DAS HEURÍSTICAS NO JULGAMENTO E NA TOMADA DE DECISÃO SOB INCERTEZA. Estudos de Psicologia, vol. 23, n. 2, p. 181-189, Campinas. 2006. 


\section{CAPITULO Teoria dos Jogos e Processo Decisório}

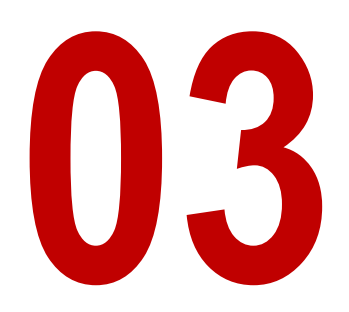

Gustavo Grana Ramos, Igor Viana dos Santos, Elizângela de Jesus

Oliveira

\section{INTRODUÇÃO}

A Tomada de Decisão é um processo constante no cotidiano de cada indivíduo. 0 ser humano está sempre submetido a situações que requerem dele uma escolha entre várias alternativas (KAWAGUCHI, YANAGISAWA \& NISHINARI, 2019). A decisão final pode ainda ser influenciada por inúmeros aspectos, inferindo desde as características do ambiente, a confiabilidade das informações e até as preferências pessoais do tomador de decisões (MENDES, MENDES \& SALLEH, 2019). Em uma situação comum, como na escolha de uma roupa para um evento à noite com os amigos, a vestimenta escolhida pode ser a mais confortável ou, ainda, aquela com mais detalhes de estampa, afinal, o encontro é entre pessoas que se veem todos os dias. Agora, continuando com a mesma situação, só que passamos a tratar de um evento promovido pela empresa, no qual um simples jantar pode firmar um acordo com uma multinacional, o mesmo grupo de amigos são colegas de trabalho representantes da empresa.

É notável o aumento na quantidade de critérios que podem ser considerados na escolha da roupa. Tornase necessário adotar uma vestimenta mais formal e que transpareça não somente seriedade na reunião com os executivos, mas transmita confiança no acordo iminente. Questões como confortabilidade ou detalhes da roupa não são mais pertinentes ao ambiente que acabara de ser formado. A situação considerada enlaça uma decisão - escolha da roupa - a fatores dos ambientes em questão - encontro com os amigos e reunião com membros da empresa. 0 processo de tomada de decisão permite chegar a um conjunto de informações que permitem explicar as ações que serão implementadas. No decorrer desse processo, algumas técnicas ou ferramentas podem auxiliar agrupando as questões consideradas importantes para a decisão.

A mudança de alguma variável, no entanto, pode influenciar na decisão tomada, como ocorreu com os efeitos da mudança de cenário na escolha da roupa para o evento. Tomando-se como referência esse contexto, a análise de sensibilidade é uma técnica que procura tornar evidente os efeitos da alteração de uma variável no resultado e, assim, possibilita ao decisor considerar as questões mais relevantes no processo de tomada de decisão. Por permitir uma visão holística de todos os fatores, o decisor dispõe de dados para embasar suas escolhas. Assim, ao se considerar o ambiente organizacional, as pessoas são partes influenciadoras do processo de decisão. As variáveis são incrementadas e os acréscimos são oriundos de percepções, cultura e experiências diversas, que quando em discordância fazem vir à tona 
conflitos de ideias. Mais do que justificar a decisão, torna-se imprescindível formar simbioses estratégicas para convencer aos demais sobre a importância de uma determinada decisão. Retornando à situação dos colegas de trabalho no jantar de negócios, é imperativo que faça sentido à multinacional a importância de uma tomada de decisão estratégica que seja lucrativa para ambos. Por outro lado, deve-se considerar a percepção dos outros participantes que serão um fator influenciador nesse "jogo estratégico" de sobrevivência organizacional.

Nesse sentido, a teoria dos jogos trata da sistematização dos esforços de caráter estratégico do ser humano em situações de interação com os demais interessados em determinada causa (SANTOS \& CARVALHO, 2017) circunscrito a um ambiente competitivo. O objetivo deste capítulo é explorar os conceitos da teoria dos jogos, a partir da visão de vários autores com a finalidade de contribuir para compreensão dos atores em um processo de tomada de decisão. Este trabalho encontra-se dividido em 3 partes, a primeira esta introdução. A segunda seção segue-se com a discussão acerca da análise de sensibilidade e teoria dos jogos, a terceira com as contribuições desse estudo e, por fim, as referências.

\subsection{ANÁLISE DE SENSIBILIDADE}

A análise de sensibilidade procura avaliar, por meio de cálculos matemáticos, resultados partindo de deslocamentos das variáveis determinantes, possibilitando que, em um contexto de tomada de decisão, seus efeitos direcionem a busca pela melhor opção mediante a várias alternativas (ZARY et al, 2015). A apresentação dos resultados por meio deste método, quando escolhido adequadamente, possibilita aos gestores a tomada de decisão no intuito de que a empresa planejadora maximize os lucros e reduza os desperdícios (PINHEIRO, et al., 2012).

$\mathrm{Na}$ abordagem de determinado problema, a análise de sensibilidade direciona a ação que melhor se enquadra na visualização de verificação de falhas, como a análise probabilística de falha, programação linear, entre outros. A análise probabilística de falha, que trabalha com variáveis em intervalos de tempo, verifica erros em produtos por meio de gráficos, possibilitando o analista encontrar facilmente o problema e armar uma solução imediata, quando for o caso (KALA, 2019). A avaliação gráfica probabilística, apesar de verificar o problema de forma bem sucinta, possibilita ver a variação de resultados do início ao fim (LEONELLI, 2019).

Os resultados da análise de sensibilidade direcionam recursos para as variáveis de grande prestígio, quando se objetiva melhorias nas atrações de investimento. É importante que a organização tenha uma visão sobre os diferentes cenários que poderá atuar, tais como os custos e despesas envolvidas, para que dessa forma possa direcionar os recursos para a decisão que apresenta os melhores resultados financeiros para a empresa (PINHEIRO et al., 2012). Dessa forma, as teorias que versam sobre o comportamento racional ou subjetivo dos tomadores de decisão devem ser conhecidas, pois em um jogo empresarial a 
melhor tática a ser utilizada definirá o caminho futuro organizacional. Na próxima seção, discorre-se sobre a importância estratégica da teoria dos jogos.

\subsection{TEORIA DOS JOGOS}

Os primeiros trabalhos sobre teoria dos jogos surgiram na metade do século XX, com os trabalhos de John Von Neumann (1903-1953) e Oskar Morgenstern (1902-1977), que juntos publicaram em 1944 o livro The theory of games and economic behavior. No Livro, esses autores recomendaram um problema conhecido como "jogo de soma zero", que tinha como objetivo armar uma competição onde o ganho de jogadores para uma dada equipe, representava a perda para a outra (SANTOS \& CARVALHO, 2017). Em seguida, vários outros autores contribuíram no estudo sobre teoria dos jogos, entre eles John Nash (19282015), que ganhou o Nobel de Economia em 1994, após vários estudos sobre equilíbrio, com foco na interação entre jogadores na tomada de decisão, onde o custo não é fixo (CONSTANTINO et al., 2016).

Bastante difundida na área econômica, a teoria dos jogos propõe-se buscar estratégias racionais onde o resultado não depende apenas do tomador de decisão, como também dos planos propostos por outros agentes envolvidos no processo decisório. Os competidores possuem chances de utilizarem estratégias similares que podem contribuir para o alcance de um resultado de excelência, ou ainda identificar estrategicamente uma determinada variável que os outros participantes não notaram (WOOLDRIDGE, 2012). Constantino et al. (2016) em seu trabalho "Cooperar ou Não Cooperar? Uma análise à luz da teoria dos jogos" elenca quatro definições iniciais para a construção da modelagem sobre teoria dos jogos: a primeira enfatiza o jogo, buscando esclarecer a sua importância no processo interativo para a tomada de decisão; a segunda diz respeito à explanação de estratégias (devem ser bem definidas) dos diferentes membros do grupo de tomadores de decisão; na terceira definição, procura-se saber se as estratégias apresentadas por cada agente são do conhecimento de todos os membros; por fim, a quarta definição, que discorre sobre equilíbrio (solução). Nessa última, afirma que a teoria consiste em um resultado que, se alcançado pelo grupo tomador de decisão, fica difícil mudar de posição, a não ser que algum fator externo possibilita esse feito.

Apesar do método apresentar conceitos e procedimentos confiáveis para a tomada de decisão, algumas limitações foram destacadas, como o privilégio na obtenção de informações que determinado membro do grupo leva em relação ao outro (HOJI et al., 2012). Esse fato deve ser analisado antes do jogo estratégico iniciar para que todos possam "jogar" em condições similares (SANTOS \& CARVALHO, 2017). A seção seguinte vai apresentar a contribuição da teoria dos jogos para o desenvolvimento do sistema que hoje se faz presente em toda organização que almeje altos índices de produtividade, melhoria de qualidade e redução de custos, o Sistema Toyota de Produção. 


\section{CONTRIBUIÇÃO - SISTEMA TOYOTA DE PRODUÇÃO}

No final da Segunda Guerra Mundial (1939-1945), os acontecimentos de Hiroshima e Nagasaki forçaram o império japonês a assinar um termo de rendição. 0 país passou a representar os interesses norteamericanos no continente asiático frente à influência do comunismo na época. 0 objetivo centrou-se na reconstrução de questões que abrangiam a economia e infraestrutura japonesa, bem como ao atendimento a aspectos de ordem social. Os empreendimentos, portanto, estavam limitados devido aos escassos recursos de matéria-prima e mão-de-obra, fato que estagnou o desenvolvimento da indústria no país, inclusive a Toyota Industries.

As primeiras vendas da empresa fundada pela Família Toyoda, no final do século XIX, resumia-se a dispositivos para tecelagem, incluindo um tear mecânico automático que possuía desempenho bastante superior aos padrões internacionais. 0 interesse pela indústria automobilística se deu com uma visita de Kiichiro Toyoda às indústrias americanas, chamando sua atenção e levando a investimentos consideráveis para o setor e criação da Toyota Motors Company. Os efeitos do conflito bélico, no entanto, interromperam o seu desenvolvimento, forçando a Toyota a se adequar às restrições financeiras que acometera a todos no país. A forma de produzir em massa, que tão bem atendia às necessidades dos consumidores americanos, tornara-se inviável em solo japonês. Para garantir a sobrevivência no mercado da indústria automobilística, era necessário produzir em bastante quantidade e ao mesmo tempo disponibilizar vários modelos do produto aos clientes. Assim, para fazer frente às limitações no fornecimento de insumos, tornara-se imperativo adotar um modelo de produção mais eficiente e que minimizasse os desperdícios.

Taiichi Onho (1912-1990) entrou para o Grupo Toyota em 1932, passando a acompanhar o operacional da empresa e seus esforços para desenvolvimento de métodos que reduzissem os desperdícios presentes nas linhas de montagem e que encurtasse o tempo de produção. $O$ aumento de produtividade foi o objetivo estabelecido para aquele jovem engenheiro. A princípio, as ações tomadas pelo gestor Ohno não foram bem recebidas pelas pessoas no chão de fábrica, como por exemplo, as mudanças no layout produtivo para permitir que o trabalhador desempenhasse várias funções ou, ainda, o uso de um dispositivo que até hoje é bem recebido em qualquer empresa e que foi desenvolvido por Ohno, a técnica Kanban (OHNO, 1988). Era compreensível tal resistência por parte dos colaboradores, afinal, a carga de trabalho estava aumentando. Ohno então defrontava-se com a necessidade de alcançar a confiança dos operadores em linha, visando garantir empenho total de todos os envolvidos nos esforços de aumento de produtividade. 0 gestor conhecera como poucos o ambiente da fábrica que gerenciara e os escritórios não o limitavam acompanhar diretamente as atividades que estavam acontecendo. É sabido que em todas as tarefas de uma organização, existem sujeitos que, direto ou indiretamente, atuam na evolução das atividades. Ohno sabia que a produção eficiente consistia em um resultado que, não somente era denotado pelo alcance de índices aceitáveis de operação, mas que também deveria ser pautado pelo respeito à pessoa. Uma organização pode ser comparada a um corpo humano que somente desempenha um trabalho suficientemente satisfatório quando se enfatiza o seu devido cuidado (OHNO, 1988). Apesar da presença 
de Ohno em ambiente operacional contar como fator importante na implementação de ações julgadas como essenciais à superação de determinados empecilhos, havia necessidade de convencer os agentes operacionais: as pessoas.

A capacidade de articulação de Ohno, envolvendo os funcionários e supervisores de operação, era principalmente baseada na bagagem que trazia consigo, afinal, os trabalhos oriundos da parceria com os Toyoda ainda perduravam na empresa. Todos os métodos utilizados e as experimentações realizadas ali, possuíam a participação de Ohno em seu desenvolvimento. Em outras palavras, a Toyota Motor Company ocupava lugar no mercado pós-guerra muito devido às contribuições de Taiichi Ohno. Deste modo, o ambiente organizacional da Toyota consistia em um cenário onde uma pessoa figurava como referência na organização, e a manutenção da empresa significava seguir o mesmo caminho daquela primeira pessoa. Assim, os colaboradores, mesmo exibindo uma certa resistência no início, acabavam por serem complacentes das ideias do gestor. Ohno poderia não relevar o fato de que um ambiente organizacional como aquele pudesse representar um cenário onde as pessoas são fatores bastante complexos, a ponto de fazer com que os âmbitos estratégico e operacional precisassem convergir em interesses específicos. Além de atuar tão bem nos dois extremos, Ohno ainda conseguira pautar seus esforços com contribuições de personalidades marcantes nas áreas de Controle Estatístico do Processo e de Qualidade, respectivamente Edward Deming (1900-1993) e Shigeo Shingo (1909-1990).

Ohno incrementou a quantidade de variáveis (que já eram muitas) usadas para embasar as suas ações, estabelecendo o Sistema Toyota de Produção nos pilares do Just-In-Time e Jidoka. Ambos transmitem a maneira da Toyota fazer, atendendo eficientemente a demanda e com produtos sem defeitos (OHNO, 1988). É notável que o cenário formado na empresa refletia as características de Ohno, facilitando ainda no prosseguimento das ações que julgara serem boas para a organização. Um bom jogador não somente dispõe suas ideias, como também modela o cenário do jogo usando as circunstâncias a seu favor.

Um outro marco que atestou os efeitos dos métodos usados na Toyota veio com a crise do petróleo em 1973. Todas as empresas japonesas se depararam com índices de crescimento nulos, obrigando-os a reduzir a produção. Os efeitos na Toyota foram atenuados devido a essa busca incessante pela redução de desperdícios, permitindo a empresa enfrentar os problemas decorrentes da crise. A partir de então, os empresários passaram a olhar com mais atenção para o que acontecia na empresa de Taiichi Ohno e como se recuperara tão rápido. Os esforços do engenheiro Ohno, que até então direcionavam o ambiente interno de uma única empresa, passariam a ser representados pela própria, só que em um contexto bem mais amplo. A Toyota Motors Company passaria a dispor de grande influência no cenário do mercado mundial, posição que é alcançada quando as estratégias são bem planejadas, as decisões bem embasadas e os demais do processo de decisão são considerados, características que são essenciais em um bom jogador. 


\section{REFERÊNCIAS}

[1] CONSTANTINO, M.; COSTA, R. B.; MENDES, D. R. F.; SILVA, E. B.; GARRUTE, M. M. Cooperar ou não Cooperar? Uma Análise à Luz da Teoria dos Jogos. Desafio Online, v. 4, n. 1, p. 135-145, 2016.

[2] HOJI, E. S.; PADILHA-FELTRIN, A.; CONTRERAS, J. Reactive control for transmission overload relief based on sensitivity analysis and cooperative game theory. IEEE Transactions on Power Systems, v. 27, n. 3, p. 1192-1203, 2012.

[3] KALA, Z. Global sensitivity analysis of reliability of structural bridge system. Engineering Structures, v. 194, p. 36-45, 2019.

[4] KAWAGUCHI, R.; YANAGISAWA, D.; NISHINARI, K. Decision-making with reference information. Physica A: Statistical Mechanics and its Applications, v. 519, p. 109-118, 2019.

[5] LEONELLI, M. Sensitivity analysis beyond linearity. International Journal of Aproximate Reasoning, v. 113, p. 106-118, Oct 2019.

[6] MENDES, F. F.; MENDES, E.; SALLEH, N. The relationship between personality and decision- making: A Systematic literature review. Information and Software Technology, v. 111, p. 50-71, 2019.

[7] OHNO, Taiic. Toyota production system: Beyond large-scale production. Productivity Press, 1988.

[8] PINHEIRO, G. R.; BARRETO, L. R.; PINTO, D. B.; RODRIGUES, M. V.; TABOSA, C. M. Método de análise de sensibilidade em uma empresa de esportes dirigidos envolvendo as ferramentas de ponto de equilíbrio e grau de alavancagem através da pacificação dinâmica. VII Simpósio de Engenharia de Produção Nordeste, Mossoró-RN, 2012.

[9] SANTOS, H. O.; CARVAlHO, E. B. S. Teoria dos Jogos: Dinâmica de Ensino dos Aspectos do Processo de Decisão. Future Studies Research Journal: Trends and Strategies, v. 9, n. 1, p. 51-77, 2017.

[10] WOOLDRIDGE, M. Does game theory work? IEEE Intelligent Systems, v. 27, n. 6, p. 76-80, 2012.

[11] ZARY, B. C. S.; HOSSMANN, M. H. S.; SILVA, B. A.; SILVA, M. A. V. Análise de alternativas de transporte de passageiro em relação ao custo e tempo de viagem. Revista Eletrônica de Ciência Administrativa, v. 13, n. 2, p. 172$184,2014$. 


\section{CAPITULO Planejamento Estratégico no Processo de Tomada de Decisão}

Carla Valéria Santos, Nediza Marques de Oliveira, Elizângela de Jesus Oliveira

\section{INTRODUÇÃO}

No ambiente organizacional em que se busca a sobrevivência de cada empresa, o planejamento estratégico destaca-se como sendo fundamental para o processo de tomada de decisão. Em um processo decisório as informações devem ser reais, aplicadas no tempo e volume certos. A decisão é parte fundamental para que a melhor alternativa seja escolhida e aplicada ao rumo futuro da organização (MARINO, 2006).

O planejamento estratégico tem como objetivo orientar as empresas e organizações nas definições de quais ações e caminhos seguir para alcançar o sucesso desejado. Somente através de um planejamento estratégico adequado é que se tem uma real visão a longo prazo do cenário a ser explorado pelas organizações (SANCHES 2018).

Em um ambiente competitivo e fluido em que os gestores e a organização buscam determinar o melhor caminho a se seguir, o processo decisório é fundamental para a realização das escolhas. Ele é determinante para a descoberta das estratégias que influenciam na sobrevivência das empresas (ZANATTA et al., 2007).

Sendo assim, em um processo decisório o sistema de informação se constitui como ferramenta de grande importância no que concerne ao suporte administrativo, pois fornece informações válidas que serão utilizadas de forma estratégica nas decisões implementadas pelos gestores (ASSIS et al., 2016).

Dessa forma, passa a ser evidente a influência que as escolhas adequadas exercem sobre o futuro de uma organização, alinhando boa gestão e tomada de decisão com o planejamento estratégico e sistema de informação (PORTO \& BANDEIRA, 2006).

A importância do planejamento estratégico incorporado com o sistema de informação gerencial das organizações influencia em cada etapa do processo, pois facilita a analise de cada etapa do trabalho desenvolvido dentro da organização (SCHEBELESKI, 2014).

O objetivo deste trabalho é abordar de forma elucidativa como o planejamento estratégico acopla-se ao sistema de informação como forma estratégica de auxiliar às tomadas de decisões em um ambiente organizacional competitivo. Este capítulo encontra-se dividido em três seções, sendo esta a introdução. A segunda a discussão teórica, seguida da terceira onde se discute as contribuições deste estudo e por fim apresentam-se as referências. 


\section{PLANEJAMENTO ESTRATÉGICO E SISTEMA DE INFORMAÇÃO}

O Sistema de Informação vem ser um grande aliado do Planejamento Estratégico, uma vez que os avanços tecnológicos proporcionam para a organização, informações reais válidas, enxutas e no tempo certo para serem aplicadas nas decisões das empresas, com a finalidade de alcançar o objetivo organizacional (BARBOSA \& SANTOS, 2005).

A tomada de decisão busca por meio diversos caminhos optar por uma melhor alternativa que alcance $o$ resultado planejado e esperado pela organização. Deve ser realizado com muita acurácia uma analise das escolhas e das condições de certeza, incertezas e de riscos presentes no ambiente organizacional (SCHEBELESKI, 2014).

O objetivo deste capitulo é apresentar uma visão sobre a importância do planejamento estratégico aliado ao sistema de informação. Uma vez que dentro do contexto de produção o planejamento estratégico submete-se constantemente ao processo de tomada de decisão (ASSIS et Al, 2016).

De acordo com os autores Bazzotti e Garcia (2018) o planejamento estratégico pode ser conceituado como um processo decisório que inclui informações validas que tem como objetivo alcançar a solução ótima que irá nortear as ações futuras das organizações.

É importante ressaltar que o planejamento estratégico é utilizado como uma das ferramentas que mais se destaca na área organizacional, envolvendo capacidade e habilidades para lidar com cenários diferentes (SCHEBELESKI, 2014).

Considerando-se o ritmo acelerado da evolução tecnológica, como a indústria 4.0, pode-se afirmar que o planejamento estratégico acopla-se ao sistema de informação da empresa em busca de melhores alternativas no processo decisório (LEÃES; ALBANO, CASSENEGO, 2018).

Quando se aborda o planejamento estratégico e sistema de informação é fundamental compreender o significado da indústria 4.0 para o mercado industrial. Destaca-se a quarta geração da revolução industrial como sendo o ponto de partida de relevantes avanços industriais, como por exemplo a tecnologia robótica de automação (PORTO \& BANDEIRA, 2006).

Para os autores Barbosa e Santos (2005), o sistema de informação pode ser conceituado como um conjunto de ferramentas tecnológicas que possibilite a comunicação dos processos. Nesse sentido, o sistema de informação é utilizado como uma ferramenta de gestão primordial no desenvolvimento tecnológico das grandes empresas, pois reduz a incidência de erros humanos.

A produção continua está diretamente ligada ao alto grau de automatização, pois envolve processo de padronização dentro da empresa, sendo uma grande ferramenta na área administrativa (PERALES, 2001). A qualidade do produto envolve a satisfação das necessidades do mercado, devido esse fator é imprescindível um olhar criterioso para os processos de produção na indústria (MARINO, 2006). 
As empresas por meio de suas matrizes em diversos países tem como foco está possibilitando um processo continuo de melhoria que é alimentado pela ação retroativa das informações agregadas em um SIG sustentável e estratégico e que requer um processo de decisão situacional (QUEIROZ; CARVALHO, 2005). É importante ressaltar que o delineamento de um planejamento por parte de uma empresa, implicará em possibilidades de maior lucratividade no seu ramo de atuação (SCHEBELESKI, 2014).

Quando o sistema de informação alia-se ao planejamento estratégico, o resultado reflete-se na produção de oferta de serviços ou produtos com maior qualidade competitiva. Nesse contexto, destacam-se ainda as ferramentas de comunicação que estão tendo avanços cada vez mais importantes nas indústrias atuais (SCHEBELESKI, 2014).

Um exemplo é a indústria 4.0 que se expandiu de uma forma bastante agressiva, fornecendo a disseminação dos dados estratégicos no processo decisório, aumentando a sua capacidade de produção em menor tempo e custo e com o máximo de qualidade (BARBOSA; SANTOS, 2005). A busca de qualidade contínua acopla-se ao que foi planejado, tal informação é alinhada de forma estratégica e em tempo real pelos Sistema de informação gerencial - SIG (LEÃES; ALBANO, CASSENEGO, 2018).

Destaca-se a importância da gestão de negócios como sendo uma área da engenharia de produção que tem como característica o gerenciamento da administração dentro da organização, pois envolve o crescimento da produção por meio da aplicação de diversas ferramentas administrativas no processo decisório (PERALES, 2001).

De acordo com ASSIS et Al (2016) os processos decisórios podem influenciar diretamente na relação entre cliente e empresa, ao buscar uma melhor alternativa de escolha para avançar em direção a um segmento específico de mercado.

Para Perales (2001) define-se mercado como um fluxo comercial de negócios expansivos de produtos com qualidade, de baixo custo e larga utilização de tecnologia de ponta.

Assim, a tomada de decisão acompanha o fluxo comercial dos produtos, pois é um recurso efetivo para o planejamento dentro de uma empresa. Uma vez que a decisão influencia o desempenho por buscar solucionar uma discrepância no contexto da organização (BARBOSA; SANTOS, 2005).

De acordo com os autores Junior e Saltorato (2018) a solução de um problema é um processo de tomada de decisão em equipe, pois deve-se levar em consideração diversos fatores. Na próxima seção discute-se um case prático como forma de demonstrar a aplicabilidade das propostas teóricas que foram apresentadas.

\section{CASES (CONTRIBUIÇõES DO ESTUDO)}

É apresentado um relatório técnico da companhia elétrica do estado do Amazonas, que opera nos sistemas isolados da Região Norte. A empresa terceirizada que presta serviço para a mesma é uma companhia especializada em construção civil, infraestrutura e energia elétrica. 
Por meio de um planejamento estratégico aliado ao sistema de informação é possível utilizar um processo contínuo metodológico de produção, tornando realidade os processos de envio de leituras aos municípios do estado do Amazonas. Este processo é estruturado em três etapas que incluem as fases de geração, agregação e envio de informações contidas no planejamento aos leituristas da região.

A Amazonas Energia gera e agrega as rotas ou corridas no sistema de informação conhecido como AJURI (o sistema de gestão comercial padronizado pela Eletrobrás) através dos analistas de sistema. 0 supervisor da empresa terceirizada por sua vez envia do sistema Ajuri para o sistema FatReal ou Repasse (permite o processamento, execução e retorno a Amazonas Energia), onde é planejado as corridas divididas em discos conforme planilha de controle de rotas.

É importante definir metas de produção por meio de um mecanismo sistemático direcionado ao planejamento estratégico, em que as corridas são agrupadas em discos no sistema e enviado aos coletores dos leituristas. No final do processo de leitura o supervisor recebe as corridas realizadas pelos leituristas, finaliza o processo no sistema FatReal ou Repasse e retorna ao sistema Ajuri concessionária da Amazonas energia.

E importante ressaltar que todo o planejamento estratégico da empresa da região norte, compreende uma etapa de produção de serviços relacionados ao sistema de informação da Amazonas energia. Esse sistema busca os melhores resultados nos processos contínuos de produção/serviços e de gerência estratégica da empresa.

O planejamento estratégico ocorre desde a etapa inicial quando a corrida é liberada no sistema AJURI que por sua vez gera o rol de leituras, enviado aos leituristas através de um dispositivo eletrônico conhecido como coletor. Dessa forma, é possível realizar um bom planejamento estratégico de longo e curto prazo de tempo de operacionalização de atendimento às rotas definidas.

As corridas são liberadas de acordo com o calendário mensal da Eletrobrás que estão programadas em planilhas no Excel. Estas planilhas são verificadas pelo supervisor do setor no polo da região norte. Ressalta-se ainda, que ao utilizar um sistema de informação integrado ao planejamento estratégico a Amazonas energia pode controlar e determinar as oportunidades e ameaças do ambiente externo, sobre o qual a empresa não tem total controle como as mudanças de tempo ou ocorrências de temporais, que podem influenciar na prestação do serviço.

O presente trabalho teve como objetivo analisar como a empresa Amazonas Energia delineia seu planejamento estratégico aliado ao sistema de informação com a finalidade de prestar melhor serviço no menor tempo aos seus clientes. Além de ter um olhar cuidadoso no processo de prestação de serviço por meio deste relatório técnico, foi possível ainda analisar os gargalos de produção no tempo estimado e no tempo não estimado. Em seguida é apresentado os gargalos identificados e as possíveis soluções para melhoria no processo produtivo da empresa. 
- Chuva que é um fator que impede as leituras em tempos sazonais de produção.

- Manutenção de equipamentos como coletores, que necessitam ser substituídos por modelos mais avançados para facilitar a leitura e ter um melhor controle da produção da empresa.

- Estoque de baterias de coletores para cada leiturista, pois foi observado que o equipamento não suporta o suficiente para aumentar a produção.

- Melhoria em relação aos equipamentos EPI's de segurança.

Portanto por meio desta analise de estudo foi apresentado o processo de prestação de serviço e os gargalos que impedem que a meta de produção seja atingida. Sugere-se para pesquisas futuras, o aumento do prazo de datas de leituras, pois existe o fator de sazonalidade da chuva que em determinados períodos impedem uma produção significativa. Outro ponto importante é o investimento em equipamentos mais avançados para os leituristas retornarem ao sistema pelo equipamento de forma mais rápida e prática. Por fim, destaca-se que todas as decisões envolvidas para a melhoria da prestação de serviço na Amazonas energia irá requerer uma ação conjunta de todos os gestores da empresa.

\section{REFERÊNCIAS}

[1] ASSIS, Débora Figueiredo de Oliveira.; AGUIAR, Luane da Conceição; ÁVILA, Silvia Regina Starling Assad de. Integração entre sistemas de informação (SI) e planejamento estratégico (PE): Um estudo realizado na empresa RR Hortifrutigranjeiros. VIII Simpósio Nacional de Tecnologia em Agronegócio. Jales, São Paulo, 2016.

[2] BARBOSA, Welton de Castro; SANTOS, Adilson Jorge dos. Planejamento estratégico de sistemas de informação para organizações do terceiro setor. XII Simpósio de Engenharia de Produção. Bauru, São Paulo, 2005.

[3] BAZZOTTI, Cristiane; GARCIA, Elias. A importância do sistema de informação gerencial na gestão empresarial para tomada de decisões. Ciências Sociais Aplicadas em Revista, Marechal Cândido Rondon, v.6, n.11, p.1-18, 2006.

[4] LEÃES, Walter Paim, ALBANO, Cláudio; CASSANEGO, Paulo. Planejamento estratégico em tecnologia da informação: um estudo dos planos diretores de tecnologia da informação das IFES. In: XVI Mostra de Iniciação Cientifica, Pós-Graduação, Pesquisa e Extensão, Caxias do sul, 2016.

[5] MARINO, Lúcia Helena Fazzane de Castro. Gestão da Qualidade e Gestão do conhecimento: fatoreschave para produtividade e competitividade empresarial. XIII Simpósio de Engenharia de Produção. Bauru, São Paulo, 2006. 
[6] PERALES, Wattson. Classificações dos sistemas de produção. In:XXI Encontro Nacional de Engenharia de Produção, 2001, Salvador-Ba. XXI Encontro Nacional de Engenharia de Produção,2001.

[7] PORTO, Maria Alice Guedes; BANDEIRA, Anselmo Alves. O processo decisório nas organizações. XIII Simpósio de Engenharia de Produção. Bauru, São Paulo, 2006.

[8] QUEIROZ, Sérgio; CARVALHO, Ruy de Quadros. Empresas multinacionais e inovação tecnológica no Brasil. São Paulo em Perspectiva, v.19, n.2, p.51-59, abr./jun. 2005.

[9] SANCHES, Osvaldo Maldonado. Planejamento estratégico de sistemas de informação gerencial. Revista de Administração Pública, Rio de Janeiro: FGV,1997.

[10] SCHEBELESKI, Marcos. Planejamento estratégico da tecnologia da informação na universidade estadual do Paraná-Unespar/Campo Mourão. IX Encontro de Produção Cientifica e Tecnológica. Campo Mourão, Paraná, 2014.

[11] ZANATTA, Alessandra; ALBARELLO, Cristiane Botezini; DE CESARO, Nestor Henrique. Sistemas de informação e o processo decisório: Um estudo de caso. Revista de Administração, v.6, n.10, 2007. 


\section{CAPITULO Análise dos estilos de tomada de i5enharia}

Hugo Glória Pantoja, Everton Jucelin Braz Gonçalves, Elizângela de Jesus Oliveira

\section{INTRODUÇÃO}

Seja no meio profissional ou no meio pessoal, decisões precisam ser tomadas diariamente, decisões que interferem diretamente no futuro do indivíduo ou da organização. Diversos autores definem de forma semelhante o processo de tomada de decisão, voltando em sua maioria para o aspecto empresarial, como sendo uma resposta à um fato, se relacionando com o desempenho futuro da organização (FILHO, SILVEIRA, SANT'ANA, 2014).

A tomada de decisão nem sempre é executada de forma racional, assim como nem sempre é tomada de forma repentina. Segundo Filho, Silveira e Sant'Ana (2014), a decisão é influenciada por fatores ambientais, organizacionais e fatores específicos de decisão, onde o fator ambiental é definido por influência da economia; os fatores organizacionais se dão por meio de estratégias passadas já adotadas pela empresa ou pela forma que a organização foi ou está estruturada; e os fatores específicos de decisão, que possibilitam o indivíduo tomar decisão de acordo com o grau de urgência, de incerteza de futuro ou de acordo com a racionalidade do tomador de decisão.

Outros autores, como Gambetti e Giusberti (2019) partem da premissa de que o indivíduo é influenciado pela emoção e pela razão e que, depende do estilo cognitivo de cada um, ou seja, da forma que cada um processa a informação. Dessa forma, a tomada decisão sofre influência dos meios externo e interno, não sendo sempre uma decisão individual, principalmente quando o indivíduo está inserido em um contexto organizacional (ABUBAKAR et. al. 2019). No ambiente universitário, tais situações que envolvem um processo decisório não é diferente do meio empresarial, já que envolvem processos e pessoas, procurando entregar o melhor produto ou serviço para o cliente ou discentes. Vale destacar que os centros universitários são de grande importância para a sociedade, pois são deles que emanam os futuros gestores formados para tomar importantes decisões, seja em prol de benefícios individuais, ou e em prol de instituições públicas ou privadas.

A partir disso, é de suma importância conhecer também os estilos de tomada de decisão dos profissionais que estão sendo desenvolvidos nessas instituições, considerando-se que os estilos se relacionam à personalidade e ao contexto de cada um (VIEIRA, 2011). Considerando tais pressupostos teóricos, as perguntas que norteiam esse estudo são: Há uma grande discrepância entre os estilos de liderança de 
estudantes da mesma área, porém de cursos diferentes? Ou os estilos se assemelham conforme a área de estudo e atuação dos discentes?

Este capítulo tem por objetivo identificar os estilos de tomada de decisão de alunos finalistas dos cursos de Engenharia e como esses estilos irão interferir no meio acadêmico e no mercado de trabalho. Assim, apresenta-se na primeira seção a introdução, como forma de familiarizar o leitor com o assunto abordado. Na segunda seção são expostos conceitos sobre a tomada de decisão, os fatores que influenciam a tomada de decisão e os estilos de decisão que a literatura dispõe. Na terceira seção são discutidos os resultados e seguem-se as referências.

\section{REFERENCIAL TEÓRICO}

\subsection{PROCESSO DE TOMADA DE DECISÃO}

Para Dalcin (2013), a tomada de decisão é um processo de aprendizagem e é um ponto básico na administração e gestão empresarial. Este processo muitas vezes é embasado na tentativa e erro do indivíduo, envolvendo suas crenças, seus valores e tradições, ou ainda é definido pelo conhecimento, limitações e informações acerca do objetivo que se espera alcançar. Uma decisão é tomada de acordo com a capacidade cognitiva e de raciocínio do indivíduo. Fagundes, Ensslin e Schnorrenberger (2018) relacionam o processo de tomada de decisão com uma ação de causa e efeito, onde o indivíduo é forçado a tomar uma decisão quando submetido a situações de risco.

Dewberry, Juanchich e Narendran (2013), pontuam que a tomada de decisão é influenciada pela personalidade do indivíduo, no qual fatores como ansiedade e impulsividade afetam a natureza da decisão. No âmbito organizacional, o dogmatismo e o absolutismo corporativo norteiam a cognição do decisor e como os indivíduos envolvidos no processo respondem aos estímulos para que haja confiança cognitiva visando a eficácia da decisão tomada.

Existem vários pontos de vistas para qual sejam os estilos de tomada de decisão. Muitos deles utilizam os cinco estilos propostos por Scott e Bruce (1995), pontuando os estilos como: racional, intuitivo, procrastinador e espontâneo, que é o mais encontrado na literatura. Porém, Abubakar et. al (2019) cita apenas dois estilos para o tomador de decisão, o intuitivo, que se baseia nos seus sentimentos, sem muito embasamento numérico, e o racional, que analisa cenários alternativos e a avaliação individual de cada um para enfim chegar a uma decisão.

\subsection{OS ESTILOS DE TOMADA DE DECISÃO}

Segundo Corrêa (2013), a análise das informações que levam à tomada de decisão está diretamente ligada ao estilo do decisor, ou seja, dependendo da forma na qual as informações são apresentadas e como o 
decisor as aborda afetam em sua escolha. Os estilos de tomada de decisão podem variar de acordo com o que se leva em consideração, por exemplo, existem estilos de decisão de acordo com o uso da informação, com a escolha dos resultados ou até mesmo por dimensões.

Os estilos de tomada de decisão são mutáveis de acordo com a geração no qual o indivíduo decisor se encontra. 0 ambiente, a tecnologia e o estilo de vida da geração em que vive fazem com que a visão para a tomada de decisão seja única para cada pessoa (LADEIRA, 2010).

Tomando como base os estilos de tomada de decisão por dimensões, Almeida, Alves e Reis (2010) trazem o a abordagem de que a tomada de decisão está inserida em duas dimensões: Tolerância a ambiguidade e modo de pensar. A tolerância a ambiguidade se dá pela forma de organização no processamento das informações, tendo quem sinta a necessidade de estruturá-las de forma que não haja ambiguidade e há que consiga processar várias informações ao mesmo tempo. 0 modo de pensar se dá pela forma na qual as informações serão processadas, podendo ser de forma lógica e racional ou de forma criativa e intuitiva. Dentro dessas duas dimensões, mostradas no diagrama (Figura 1), encontram-se os estilos de tomada de decisão que serão abordados neste capítulo, sendo: analítico, conceitual, diretivo e comportamental.

Figura 1 - Diagrama de estilos de decisão

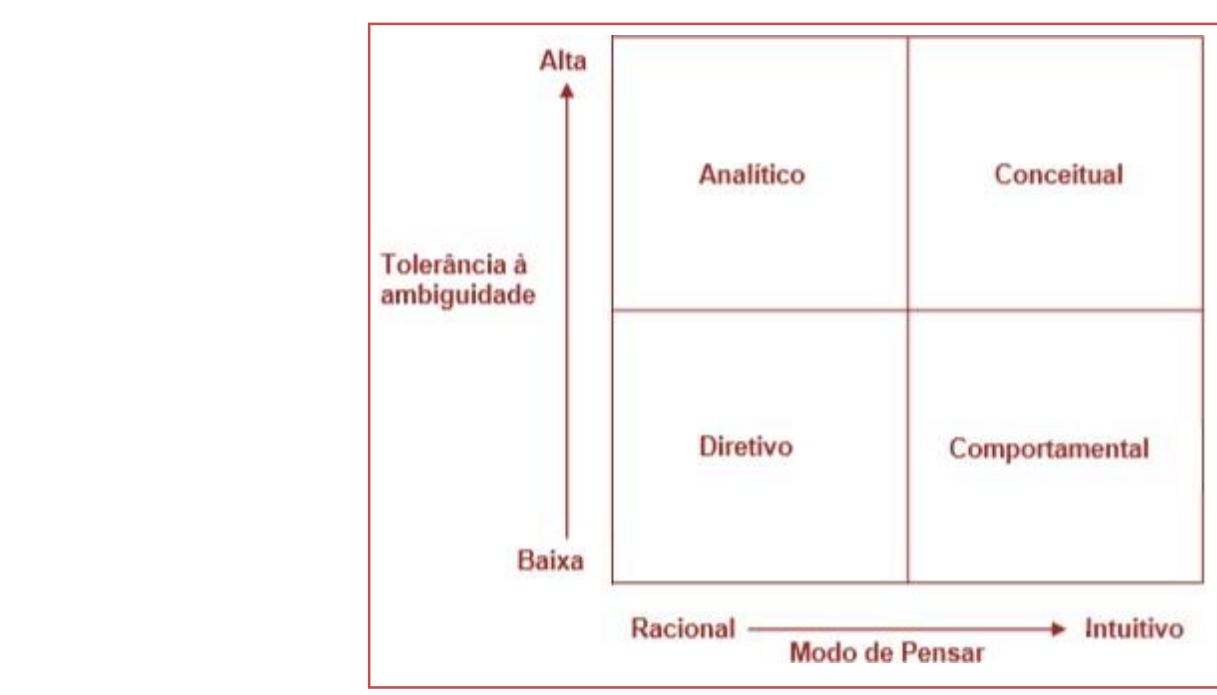

Fonte: Robbins, Stephen Paul, Administração: mudanças e perspectivas (tradução Cid Knipel Moreira).

São Paulo (2000. p. 74).

\section{METODOLOGIA}

No intuito de conhecer os estilos de tomada de decisão de alunos que estão no último ano da graduação de engenharia e visando pontuar que tipo de profissional o mercado irá absorver, nesta pesquisa utilizou-se quatro estilos propostos por Robbins (2000). Aplicou-se uma pesquisa do tipo descritiva e quantitativa 
utilizando uma survey que é utilizada quando o intuito é coletar dados quantificáveis (MARTINS, C; FERREIRA, M, 2011).

É descritiva, segundo Oliveira (2011), pois busca descrever características pessoais ou de grupos de uma determinada população e é quantitativa uma vez que trabalha com dados numéricos como forma de classificação e análise dos resultados obtidos (PRAÇA, 2015). 0 questionário utilizado neste trabalho, partiu de Almeida, Alves e Reis (2010) com alunos que estavam no último ano da graduação de Engenharia, não se restringindo à apenas uma instituição de ensino. Optou-se por analisar apenas os alunos finalistas de engenharia para que não ocorresse o efeito framing, onde a tomada de decisão é influenciada pela forma que as informações são apresentadas, já que segundo KRUGER et. al. (2018), a variável período em que o estudante se encontra na graduação influencia diretamente na escolha da decisão.

O questionário foi hospedado na plataforma SURVIO e tinha como objetivo identificar o estilo de tomada de decisão de estudantes de engenharia que estão prestes a entrar no mercado de trabalho. 0 questionário proposto foi estruturado e dividido em 20 perguntas, cada pergunta continha quatro colunas com questões, cada coluna representando um estilo, ou seja, coluna I - diretivo, coluna II - analítico, coluna III conceitual, coluna IV - comportamental. Cada coluna deveria ser pontuada de acordo com o grau de proximidade com a personalidade do estudante, sendo a pontuação a seguinte:

- 8 = MUITO parecida com o estudante

- 4 = MODERADAMENTE parecida com o estudante

- 2 = LIGEIRAMENTE parecida com o estudante

- 1 = NÃO É NADA parecida com o estudante

Ao final do questionário, foi somada a pontuação de cada coluna. 0 estilo predominante dos estudantes foi o da coluna que obteve a maior pontuação somada. Foi obtido, também, o estilo dominante dos estudantes separados por curso, visto que a engenharia possui várias áreas de atuação.

\section{ANÁLISE E DISCUSSÃO DOS RESULTADOS}

A pesquisa resultou em um total de 31 respostas, reunindo discentes dos cursos de Engenharia de Produção, Engenharia de Software, Engenharia Sanitária, Engenharia Elétrica e Engenharia Química. A divisão das respostas se encontra no Gráfico 1. 
Tomada de (In) decisão nas Organizações

Figura 1 - Percentual de entrevistados por curso

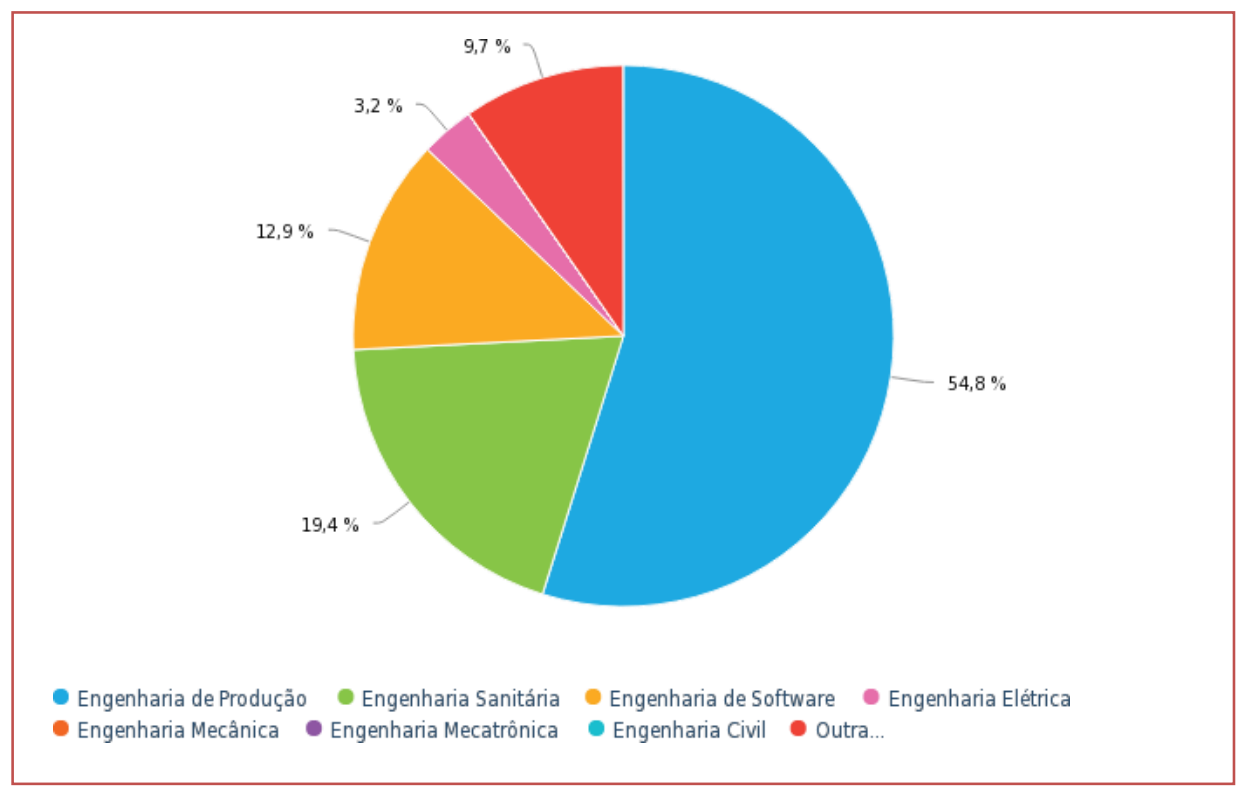

Fonte: próprio autor.

Fazendo a análise dos dados seguindo os critérios estabelecidos por Almeida, Alves e Reis (2010), chegouse aos valores apontados no Gráfico 2 .

Gráfico 1 - Pontuação geral dos estilos de decisão

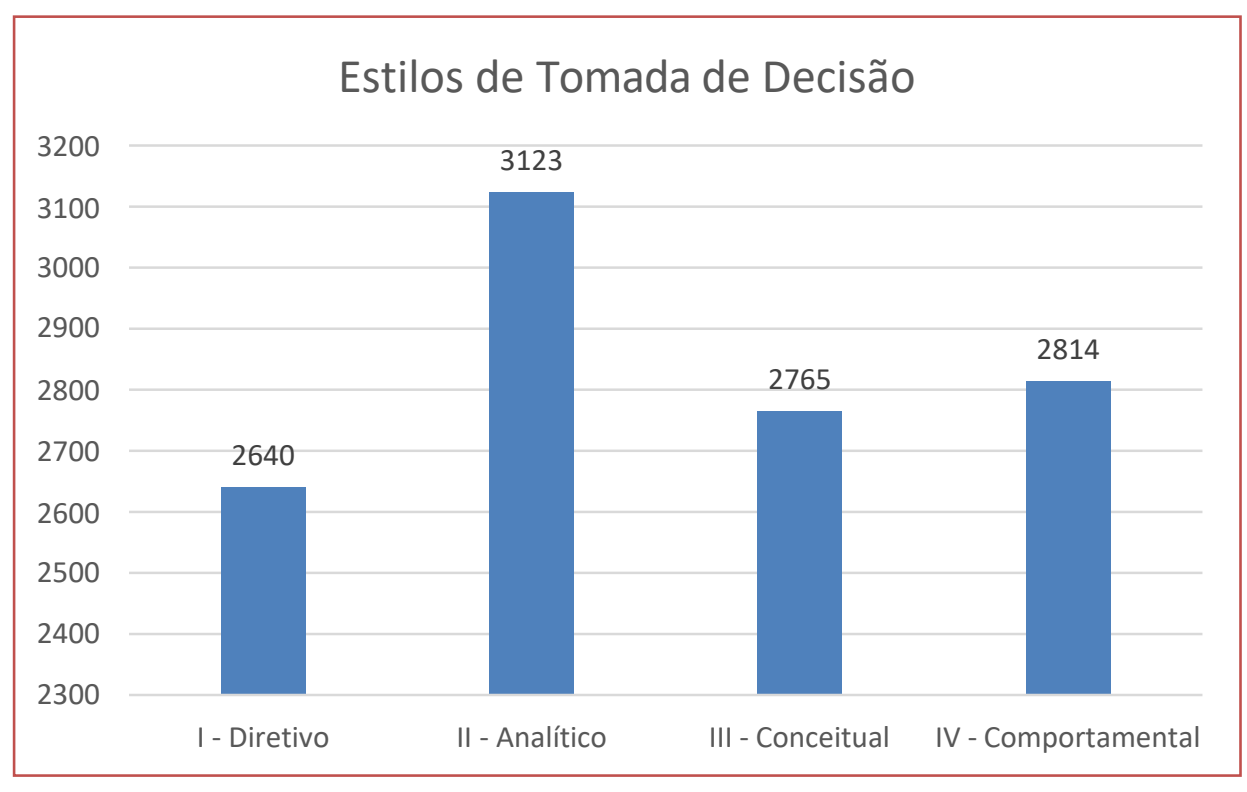

Fonte: próprio autor 
Percebe-se que o estilo de decisão que mais pontuou entre os estudantes de engenharia que responderam o questionário foi o Analítico, que se caracteriza pela cautela antes de tomar uma determinada decisão (ALMEIDA; ALVES; REIS,2010). Por meio desse gráfico é possível identificar que o estilo Diretivo, aquele que não se baseia em dados e avalia poucas alternativas, tomando decisões com base na intuição, é o que menos se assemelha à personalidade dos entrevistados (ALMEIDA; ALVES; REIS,2010).

É importante dissociar os dados gerais obtidos, em grupos menores separados por cursos, visando saber o perfil de estilo individual de cada curso, como mostra o Quadro 1, já que as engenharias possuem focos diferentes.

Quadro 1 - Pontuação dos estilos por curso

\begin{tabular}{|l|c|c|c|c|c|}
\hline & $\begin{array}{c}\text { Engenharia } \\
\text { Sanitária }\end{array}$ & $\begin{array}{c}\text { Engenharia } \\
\text { de Produção }\end{array}$ & $\begin{array}{c}\text { Engenharia } \\
\text { Química }\end{array}$ & $\begin{array}{c}\text { Engenharia } \\
\text { Elétrica }\end{array}$ & $\begin{array}{c}\text { Engenharia de } \\
\text { Software }\end{array}$ \\
\hline I - Diretivo & 530 & 1393 & 294 & 70 & 353 \\
\hline II - Analítico & 652 & 1659 & 327 & 107 & 396 \\
\hline III - Conceitual & 521 & 1510 & 283 & 55 & 379 \\
\hline IV - Comportamental & 479 & 1578 & 303 & 75 & \\
\hline
\end{tabular}

Fonte: próprio autor

Nos cursos identificados na pesquisa, exceto o de engenharia de software, prevaleceu o estilo analítico, que segundo o autor supracitado, estudantes de Administração, gerentes e altos executivos tendem a possuir esse estilo de tomada de decisão. Os discentes de engenharia de software, se identificam com o estilo conceitual, que ainda segundo Almeida, Alves e Reis (2010) possuem enfoque a longo prazo, dando ênfase na criatividade individual para tomar decisão. Essa decisão pode ser explicada pela constante mudança no cenário da tecnologia da informação com a migração para a Indústria 4.0, que exige uma perspectiva ampla de habilidades pessoais e interpessoais (JUNIOR; SOLTORATO,2018).

\section{CONSIDERAÇÕES}

Por meio deste trabalho foi possível identificar os estilos de tomada de decisão de estudantes no último ano da graduação de engenharia. Pôde-se perceber que os entrevistados possuem tendência ao estilo analítico, agindo com mais racionalidade ao tomar certas decisões.

Dessa forma, o objetivo do trabalho foi atingido, mostrando que o mercado tende a absorver engenheiros mais racionais e que a engenharia é uma área muito ampla, havendo variação de estilos de decisão entre os cursos. Estudos posteriores podem se ater ao estudo não somente da engenharia, mas de outras áreas também, a fim de conhecer os profissionais que ingressarão no mercado de trabalho, seja no meio industrial ou acadêmico. 


\section{REFERÊNCIAS}

[1] ABUBAKAR, A.; ELREHAIL, H.; ALATAILAT, M.; ELÇI, A. Knowledge management, decision-making style and organizational performance. Journal of Innovation \& Knowledge, 2019.

[2] ALMEIDA, A.P.; ALVES, C.; REIS, G. O Processo de tomada de decisão: Adoção de sistemas de apoio à decisão no jogo de empresas. VI Congresso Nacional de Excelência em Gestão. Niterói, 2010.

[3] CORRÊA, Luciana S. Estudo do perfil gerencial do decisor para tomada de decisão em projetos. Dissertação (Mestrado) - Universidade Federal de Pernambuco. CTG. Programa de Pós-Graduação em Engenharia de Produção, Recife, 2013.

[4] DALCIN, Dionéia. Os estilos de tomada de decisão e o desempenho econômico das propriedades rurais de Palmeira das Missões/RS. Tese (Doutorado) - Universidade Federal do Rio Grande do Sul, Centro de Estudos e Pesquisas em Agronegócios, Programa de Pós-Graduação em agronegócios, Porto Alegre, 2013.

[5] DEWBERRY, Chris; JUANCHICH, Marie; NARENDRAN, Sunitha. Decision-making competence in everyday life: The roles of general cognitive styles, decision-making styles na personality. ELSEVIER, 2013.

[6] FAGUNDES, E.; c, S.; SCHNORREnBERGER, D. Avaliação De Desempenho Dos Estilos De Decisão: Análise Da Literatura E Oportunidades De Pesquisa. Revista Eletrônica Científica do CRA-PR, 2018.

[7] FILHO, N.; SILVEIRA, F.; SANT’ANA, P. O Processo de Tomada de Decisão Para a Seleção de Projetos em uma PME do Setor De Engenharia. Revista de Gestão e Processos, 2014.

[8] GAMBETTI, E; GIUSBERTI,F.Personality, decision-making styles and investments. Journal of Behavioral and Experimental Economics. Bologna, 2019.

[9] JUNIOR, G.;SOLTORATO, P. Impactos Da Indústria 4.0 Na Organização Do Trabalho: Uma Revisão Sistemática Da Literatura. Revista Produção Online. Florianópolis, 2018.

[10] KRUGER, S.; PRESTES, M.; Mazzioni, S.; PETRI, M.Processo decisório sob efeito de preferências: Aversão e exposição ao risco . Revista Contemporânea de Contabilidade. Florianópolis, 2018.

[11] LADEIRA, Wagner J. Estilos de Tomada de Decisão: Uma Investigação em Gerações Diferentes. Revista de Administração da UNIMEP, Piracicaba, 2010.

[12] MARTINS, C.; FERREIRA, M. O Survey como tipo de pesquisa aplicado na descrição do conhecimento do processo de gerenciamento de riscos em projetos no segmento da construção. VII Congresso Nacional de Excelência em Gestão, 2011.

[13] OLIVEIRA, Maxwell. Metodologia Científica: um manual para a realização de pesquisas em Administração. Universidade Federal de Goiás: Catalão, 2011.

[14] PRACA, Fabiola. Metodologia da Pesquisa Científica: Organização estrutural e os desafios para redigir o trabalho de conclusão. Diálogos Acadêmicos. Ribeirão Preto, 2015.

[15] VIEIRA, V. Evaluating the Psychometric Properties of Consumer Decision-making Style Instrument. R. Adm. FACES Journal Belo Horizonte, 2011. 


\section{Perspectiva da Gestão de Pessoas}

Elizângela de Jesus Oliveira, Alice Nascimento Teixeira Rocha, Gleica Soyan B. Alves, Anderson Lincoln Vital.

A Gestão de Pessoas (GP) teve seu início no final do século XIX, com o americano Frederick W. Taylor (1856-1915) e o francês Jules Henri Fayol (1841-1925) que foi marcado pelo movimento da Administração Científica. Embora os pioneiros tivessem quilômetros de distância e partindo de ideias dessemelhantes, seus objetivos eram comuns na busca de melhorar a eficiência dos trabalhos nas fábricas, com isso, elaboraram teorias acerca da administração sendo conhecida atualmente como Abordagem Clássica.

Todavia, as influências da Gestão de Pessoas foram praticadas pelas soberanias que já predominavam na época como igrejas católicas e organizações militares. 0 domínio era de artesões que realizavam trabalhos individualmente, juntamente com profissionais liberais e pequenas entidades como escolas, armazéns e comércios varejistas. 0 prestígio era dado aos cientistas que definiam métodos e formas através estudos científicos, e os filósofos através do pensamento humano e da racionalidade.

Para Chiavenato (2014), a evolução da atividade laboral do ser humano foram sucedidas de acordo com a história da humanidade, dessa forma, é fundamental que se desdobra as maiores influências que geraram o surgimento das organizações formais modernas. Essas intervenções que trouxeram o desenvolvimento das estratégias humanas facilitaram para a Gestão de Pessoas e tornando uma concepção essencial para as empresas. Com base na descrição do autor, será sintetizado as influências que a GP percorreu durante épocas.

São vários os fundamentos, contudo os Filósofos são os primeiros nessa evolução da Gestão de Pessoas, na qual expõe seu ponto de vista sobre a habilidade pessoal separada do conhecimento técnico e da experiência e desenvolveram o entendimento do Estado com a sociedade e o papel do homem nas organizações, as relações dos empregados com o empregador através da alienação e etc. Nesse segmento, surgem os cientistas com a racionalização do trabalho nos estudos científicos e áreas afins que serviram de base para as organizações, sejam eles matemáticos, físicos, químicos e etc., que geraram uma organização integrada que interage com o ambiente a partir das organizações orgânicas que interagiam entre si com o todo.

Outra grande influência foram as igrejas católicas em meados do século XIX e no início do século XX faziam parte das grandes organizações que partilhavam recursos e ideias da GP, sendo as primeiras organizações bem-sucedidas, bem como servindo de inspiração para modelos de estrutura organizacional em linha-staff em todos os continentes. 
Assim como, as Organizações Militares que serviram de exemplo, suas estratégias táticas e recrutamento de pessoal, seleção de militares e transferência de pelotões para quartéis ou campos de batalhas, e ainda, foram associados os princípios modernos de pessoal, logística e organização provendo armamento e estoque de suprimentos (CHIAVENATO, 2014).

Entretanto, o autor descreve que o liberalismo se tornou o marco principal no século XVIII. Os Economistas Liberais desenvolveram diversas teorias econômicas acerca dos fenômenos empresariais a partir da aplicação com os operários. Em conformidade, eles dependeriam do patrão produzindo bens e serviços para a população e em troca, recebiam o recurso monetário para sobrevivência sob entendimento dos economistas liberais que controlariam o quadro de pessoal. Posteriormente, a teoria começa a se consolidar com o surgimento de inovações gerando mudanças no cenário empresarial no século XIX. São os Empreendedores Pioneiros que surgiram com a criação das empresas privadas, com poderosas ações de investimento e construção de estradas de ferro gerando emprego e renda, recrutamento e seleção e em consequência, surgindo a integração vertical nas empresas. Essa integração facilitou na comunicação e interatividade com os operários originando as primeiras departamentalizações, e fez com que as fábricas obtivessem controle das matérias-primas. Essa comunicabilidade e fluxo de comércio e consumo transformou a Inglaterra na maior potência econômica mundial em 1871.

Entre os séculos XVII e XIX, surgiu uma nova concepção de trabalho, alterando a estrutura comercial e social e provocando mudanças a ordem econômica conhecida como Revolução Industrial. A partir dessa Revolução que surgiu as teorias administrativas nas organizações em que os indivíduos tivesses eficiência na produtividade trabalhando isoladamente.

Para ter o entendimento dos desafios que a gestão de pessoas vive, é fundamental que compreenda a evolução de suas funções de recursos humanos. Desde muito antes, foram sofridas mudanças de paradigma, sociopolítica, tecnológica, entre outros que geraram novas forma de pensar e administrar. Como consequência dessas mudanças, a gestão de pessoas sofreu grandes alterações, entre eles o nome, que não se chamada "Recursos Humanos", e as relações de trabalho. Veremos quais as características dos modelos típicos de cada era e como evoluiu ao longo do tempo.

- Perspectiva de Pessoal/Relações Industriais: um órgão típico da era clássica, um tipo de Departamento que visava no cumprimento de normas e regras do pessoal, acompanhando desde a contratação, entrando na folha de pagamento, benefícios e recompensas, controle de horas até chegar a sua aposentadoria ou demissão. Vale ressaltar que o foco não estava na preocupação com o bem-estar do pessoal, pois era visto como uma espécie de máquina, algo que pudesse ser substituído e o operário não era movido por aspectos motivacionais além do dinheiro.

Perspectiva de Gestão de Pessoas: No final da era neoclássica e no início da era da informação, a gestão de pessoas deu um grande passo considerando sua mudança extraordinária que envolve toda a estrutura organizacional. Nesse contexto, as pessoas foram vistas como elementos-chave para o sucesso da organização, onde todo processo de produção se realiza com a colaboração conjunta dos diversos parceiros envolvidos, cada um contribuindo com a empresa. Sendo assim, as organizações procuram alcançar seus objetivos e buscam que os indivíduos atinjam os seus. 
- Perspectiva de Recursos Humanos: Surgiu a partir da Escola das Relações Humanas, onde as organizações passaram a ver a concepção do homem como ser humano movido por incentivos sociais e simbólicos, visando na produtividade. Começou a surgir autonomia na execução de atividades e a criação dos grupos informais. Dessa forma, o Departamento de Recursos Humanos desempenhou novas atividades como serviços especializados de recrutamento, seleção, treinamento, definição de cargos e salários, relações trabalhistas e sindicais, avaliações de desempenho, preocupação com ambiente higienizado e segurança no trabalho. Essas atividades eram desempenhadas dentro das próprias organizações em alguns casos com autonomia tendo em vista a eficácia do pessoal.

A partir das novas perspectivas, a Gestão de Pessoas se tornou a área que constrói talentos através de um conjunto constituído de processos e técnicas que cuida do capital humano nas empresas. Desse modo, a forma intelectual que a gestão de pessoas administra se tornará a base do sucesso.

Na visão de Fischer (1998), a evolução da área de recursos humanos demonstra a ocorrência de quatro modelos de gestão de pessoas nas organizações, são eles:

- Departamento de Pessoal: a função seria de registrar as pessoas, alocar no trabalho, realizar a comunicação ouvindo as reclamações, pois os gestores não ouviam. Nesse segmento, o departamento de pessoal tratava com imparcialidade e distanciamento, pois os operários eram apenas componentes da organização.

- Gestão de Comportamento Humano: trata da integração do funcionário com a organização, incorporando conceitos psicológicos, porém, tratando como sujeitos passivos assim como o dinheiro e podendo ser mobilizados para o sucesso da organização.

- Gestão Estratégica de Pessoas: busca vincular a área de gestão de pessoas aos objetivos organizacionais, demonstrando aos funcionários a capacidade de se adaptarem as mudanças da empresa e as necessidades para implementação das estratégias internas e externas. Aqui, o foco é direcionar os funcionários para os objetivos da empresa realizando as atividades da melhor maneira possível.

- Modelo de Gestão Baseado nas Competências: esse modelo busca desenvolver e/ou mapear as competências necessárias que os colaboradores possuem para que as competências organizacionais possam ser concluídas. Esse método gera crescimento a longo prazo e competitividade organizacional, pois as pessoas deixaram de ser os instrumentos estratégicos e passaram a ser os agentes estratégicos da empresa, com o desenvolvimento do trabalho orgânico, decisões descentralizadas e trabalho em equipes.

Percebe-se uma evolução da área de RH, ao longo dos séculos, mas a função de gestão de pessoas enfrenta muitos desafios, com foco no cliente, consultorias internas e etc. $\mathrm{O}$ autor afirma que houve influências nos ambientes externos para o desenvolvimento dos modelos, como questões políticas, contextos sociais, econômico e social. 
Chiavenato (2014) descreve teorias administrativas que foram essências para formação da gestão de pessoas. Os fatores percorreram as grandes organizações e foram aperfeiçoadas durante o século XX. A gestão de pessoas está inserida dentro dos contextos da administração, e a mesma surgiu a partir da Revolução Industrial. Durante esse período de mudanças na organização, foram geradas e aperfeiçoadas a aplicabilidade da gestão de pessoas dentro das teorias administrativas. As principais teorias que possuem relação com gestão de pessoas, e que o autor descreve são as seguintes:

I. Administração Científica: teoria abordada por Frederick Taylor em que via o ser humano como parte de uma grande máquina, a própria organização. 0 pioneiro relata em seu livro que enxergava o ser humano como um boi, ou seja, uma espécie de recurso que fornecia força bruta para o funcionamento da organização, e sua preocupação estava na maximização da execução das tarefas, quanto mais produzia, maior seria o desempenho da organização, e oferecia remuneração individual para motivá-los na produção.

II. Teoria Clássica: restruturada por Henri Fayol, o francês visava o mesmo objetivo da Administração Científica, maximizar a eficiência da organização. Entretanto, sua preocupação não estava no homem em execução as tarefas, mas em fazer parte da estrutura da através das divisões de trabalho, unidade de comando e direção, espírito de equipe, ordem, equidade, entre outros. No entanto, a tomada de decisão ainda era centralizada e com base nessa teoria, surgiu a estrutura organizacional que são representadas por meio do organograma.

III. Teoria das Relações Humanas: o fundado dessa teoria foi Elton Mayo conduzido pela experiência de estudar as relações de trabalho e produtividade dos operários. Sob uma concepção de Homem Social, entedia que os trabalhadores reagiam através de incentivos simbólicos e sociais, ou seja, a preocupação da organização estava no seu comportamento e suas emoções que seriam conduzidos e incentivados a um melhor desempenho no trabalho.

IV. Teoria Burocrática: nas concepções de Max Weber em 1909, compreendia que as pessoas eram meros instrumentos de máquina para a organização. Mas entre o período e 1930 a 1940 foi compreendida a concepção do homem como ser organizacional, visto que na Teoria Clássica o homem era uma espécie de máquina (Homo Economicus) e nas Relações Humanas era visto como ser social excessivamente romantizado. Logo, a teoria weberiana acreditava que a concepção do homem como ser organizacional seria a chave para o cumprimento dos objetivos da empresa, sendo organizados de forma estável conduzidos por regras, normas e procedimentos técnicos.

V. Teoria Neoclássica: teve início na década de 1950 pelas mãos de Peter Drucker na concepção do homem organizacional e administrativo. Nessa perspectiva, o homem é racional capazes de decidir, planejar e alcançar seus próprios objetivos. E ainda, é um ser sociável que aceita incentivos mistos, simbólicos e sociais com intuito de realizar os objetivos da organização.

VI. Teoria Comportamental: tem o seu início com Herbert Alexander Simon, a concepção era do homem administrativo, dotados de necessidades, de um sistema psíquico, com capacidade de articular assuntos abstratos e aptidão para aprender orientado a objetivos. Nessa teoria, são criadas as teorias de conflitos, grupos, motivação, liderança e etc. 
VII. Teoria Sistêmica: se baseia na concepção do homem complexo que acreditava no estudo recíproco de todas as necessidades de sua interação com a organização através do estudo das disciplinas, e assim passaram a tratar os objetivos de estudo como sistemas. Sua motivação era guiada por incentivos mistos de acordo com seu comportamento em que desempenhava diversos papéis na organização. De acordo com Dutra (2011) e com base nas teorias administrativas, a Gestão de Pessoas foi condicionada a administração científica durante todo o Século XX. Desde o início do Século XX quando a Abordagem Clássica trouxe visões de Taylor e Fayol, as funções da administração trouxeram fundamentos científicos acerca dos relacionamentos humanos e as concepções de trabalho que exerciam, com isso, a evolução do pensamento administrativo influenciou no desenvolvimento da função de Recursos Humano (FISCHER, 2011).

Contudo, Gil (2001) e Dutra (2011) descreve que as mudanças ocorridas desde os anos de 1980, a globalização e a informação deram impulso na Gestão de Pessoas e, começou a enxergar as pessoas como colaboradoras e parceiras, com isso gerou vantagens competitivas nas organizações. A gestão de pessoas começou a se consolidar no meio organizacional desde as perspectivas até as teorias administrativas, conhecidas atualmente como Gestão de Estratégia, Gestão de Talentos, Gestão do Capital Intelectual, Gestão do Capital Humano (GIL, 2001).

\section{REFERÊNCIAS}

[1] CHIAVEnATO, Idalberto. Gestão de Pessoas: o novo papel dos recursos humanos nas organizações. 4a Edição. Rio de Janeiro: Elsevier, 2014.

[2] CHIAVENATO, Idalberto. Introdução à Teoria Geral da Administração. 9a Edição. Rio de Janeiro, Elsevier, 2014.

[3] DUTRA, J. S. Gestão de Pessoas: modelo, processo, tendências e perspectiva. são Paulo: Atlas, 2011.

[4] FISCHER, R. A Construção do Modelo Competitivo de Gestão de Pessoas no Brasil: um estudo sobre as empresas consideradas exemplares. Tese (Doutorado) - Faculdade de Economia, Administração e Contabilidade da Universidade de São Paulo: FEA - USP, 1998.

[5] FISCHER. A. L. Um resgate conceitual e histórico dos modelos de gestão de pessoas. In: FLEUTY, M. T. L. (Coord.). As Pessoas na Organização. São Paulo: Gente, 2002.

[6] GIL, A. C. Gestão de Pessoas: enfoque nos papéis profissionais. São Paulo: Atlas, 2001. 


\section{CAPÍTULO Evolução do Conceito de Gestão de Pessoas}

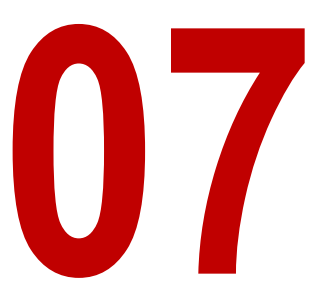

Afrânio Esquerdo Viana, Elizângela de Jesus Oliveira, Alice

Nascimento Teixeira Rocha, Gleica Soyan B. Alves, Anderson Lincoln

Vital.

Em seus primórdios, final do século XIX, a Gestão de pessoas ou Recursos Humanos, surgia com um conceito que não nos permitia defini-la como uma área específica e consolidada, mas sim como um conjunto de tarefas ou atividades que consistiam em selecionar, treinar, pagar e demitir empregados, tal cargo era denominado como Chefe de Pessoal (OGLIARA, 2015). Em seu surgimento, percebe-se que a ênfase era somente na obtenção de lucro a partir do que fosse produzido, tratando o funcionário apenas como uma pequena parte do sistema como um todo, tendo-se como verdade que o seu bem estar não influenciava na produção (OTTANI, 2017).

Em relação às atividades do Chefe de Pessoal, no início do século XX elas se consolidaram como um departamento, suas obrigações se estendiam para além daquelas que existiam no seu surgimento, pois agora o novo modelo de administração pretendia maximizar a produção a partir da redução de conflitos entre funcionários e empregadores (LIMA, 2016). Sendo assim, percebeu-se que nesse momento seu conceito nos permitia relacioná-lo a uma maior preocupação para com o indivíduo e suas necessidades, apresentando um lado um pouco mais humano para o Chefe de Pessoal (AMORIM; COMINI; FISCHER, 2019).

Com avanços no campo da Administração, a criação de novas teorias e além disso mudanças no meio externo à fábrica, a partir de 1945, extinguiu-se o cargo de Chefe de Pessoal e criou-se o de Gerente de pessoal (BARROS et al, 2016), dentre suas principais obrigações, podemos citar o olhar excessivo para a relação do empregado com a empresa, pois nesse período surgiram questões relacionadas à novas leis e movimentos sindicais (LIRA; REGINALDO; TARTARI, 2016), temos aqui uma mudança drástica de conceito, pois quem antes era visto apenas como uma peça sem muita importância, passou a ter alguém que zelasse até mesmo por sua relação com a empresa. Dessa forma o cargo de Chefe de Pessoal estava começando a evoluir para uma área que entendia a relação existente entre o bem estar do funcionário e a produção da empresa (REIS, 2016).

Por volta de 1950, houve outra revolução administrativa, pois o que antes era Chefe de Pessoal, se transformou em Gerente de Recursos Humanos, além da criação do Gerente de Relações Industriais (ARANHA; SALLES, 2015), tem-se aqui uma ramificação em que um cargo cuida da parte administrativa e o outro da parte mais humana. Fica muito evidente nesse período, a importância de tais cargos em relação à forma como a empresa trata seus funcionários (FRAGA; GEMELLI; PRESTES, 2019). 
Apesar de tais mudanças durante os períodos já mencionados, podemos perceber que a Gestão de pessoas continuava a operar em nível tático operacional, com ênfase no bem estar do funcionário e sua relação com a empresa (LOPES, 2017), o que não apresentava muita seguridade para os funcionários, que não se sentiam motivados a progredir em suas respectivas áreas de atuação. Somente por volta de 1980 que houveram os primeiros planejamentos de gestão de pessoas em nível estratégico, o que causou uma grande revolução dentro no conceito de Gestão de Pessoas, pois agora os funcionários não só participam do processo, como também possuem voz na tomada de decisão (BELTRAME et al, 2016).

Contudo, podemos observar que a Gestão de Pessoas evoluiu de um conceito totalmente "frio", em que os funcionários eram vistos como peças que não possuíam direitos, apenas deveres, para um que não enxergava funcionários, mas sim colaboradores de um grande processo. Isso é algo que se reflete na atual Gestão com Pessoas, em que empresa e colaboradores trabalham juntos para atingir um objetivo em comum, ao mesmo tempo em que é fornecido um plano de carreira para o colaborador, o que acaba gerando maximização dos lucros e uma enorme vantagem competitiva para a empresa (LIEDKE, 2018).

\section{REFERÊNCIAS}

[1] AMORIM, Wilson Aparecido Costa de; COMINI, Graziella Maria; FISCHER, André Luiz. Ensino e pesquisa em gestão de pessoas/gestão de recursos humanos no Brasil: Convergência ou divergência. RAE-Revista de Administração de Empresas, v. 59, n. 3, p. 215-221, 2019.

[2] ARANHA, João Gilberto Torres; SALLES, Denise Medeiros Ribeiro. A evolução da gestão de pessoas nas Universidades Federais: Do patrimonialismo ao estratégico. XV COLÓQUIO INTERNACIONAL DE GESTÃO UNIVERSITÁRIA - CIGU, Mar del Plata, Argentina, 2015. ISBN 978-85-68618-01-1.

[3] BARROS, Roni Storti de; COSTA, Vania Medianeira Flores; FIGHERA, Andressa; MABONI, Leonardo Alves; PARCIANELLO, José Adroaldo. Evolução da área de gestão de pessoas em uma instituição de ensino federal: Do operacional ao estratégico. Sociais e Humanas, v. 29, n. 3, p. 56-79, 2016.

[4] BELTRAME, Betina; CAMARGo, Evandro José Bilycz de; GRZYBOVSKI, Denize; LORENZON, Ana Luisa Hentges; PEREIRA, André da Silva. Gestão de Pessoas na Administração Pública Federal: Análise dos Modelos Adotados no Período 1995 a 2010. RIGS-Revista Interdisciplinar de Gestão Social, v. 5, n. 1, p. 63-87, 2016.

[5] FRAGA, Aline Mendonça; GEMELLI, Catia Eli; PRESTES, Vanessa Amaral. Produção científica em relações de trabalho e gestão de pessoas (2000/2017). CONTEXTUS - Revista Contemporânea de Economia e Gestão. v. 17, n 2, p. 222-248, 2019.

[6] LIEDKE, J. O. Gestão de recursos humanos: Uma vantagem competitiva. Dissertação (Mestrado em Gestão Empresarial) - Escola Brasileira de Administração Pública e de Empresas, Rio de Janeiro, 2018.

[7] LIMA, L. C. A relação entre o ambiente institucional, a gestão de recursos humanos e os resultados organizacionais. Tese (Doutora em Ciências) - Universidade de São Paulo, São Paulo, 2016.

[8] LIRA, Wescley José; REGINALDO, Thiago; TARTARI, Jaqueline de Souza. Imagens arquetípicas na Gestão de Pessoas. NAVUS- Revista de Gestão e Tecnologia, v. 6, n. 1, p. 6-16, 2016. 
[9] LOPES, D. P. T. Inovação gerencial na perspectiva da gestão de recursos humanos. Tese (Doutor em Administração) - Universidade Federal de Minas Gerais, Belo Horizonte, 2017.

[10] OGLIARA, M. O que dizem os líderes de recursos humanos sobre a gestão de recursos humanos. Dissertação (Mestrado em Administração de Empresas) - Escola de Administração de Empresas de São Paulo, São Paulo, 2015.

[11] OTTANI, B. S. Desenvolvimento de competências para o uso dos sistemas de informação da área de gestão de pessoas em uma universidade federal. Dissertação (Mestrado em Administração) - Universidade Federal de Santa Catarina, Florianópolis, 2017.

[12] REIS, F. A. Gestão de recursos humanos e organizações substantivas: Um estudo comparativo. Dissertação (Mestrado em Gestão Empresarial) - Escola Brasileira de Administração Pública e de Empresas, Rio de Janeiro, 2016. 


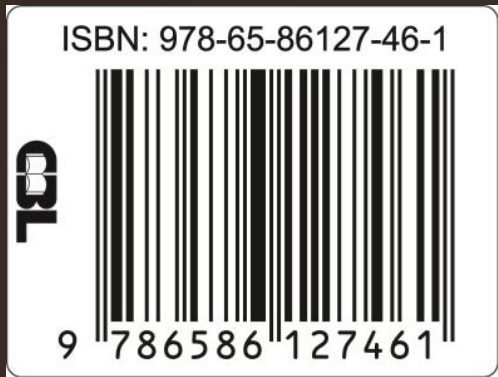

